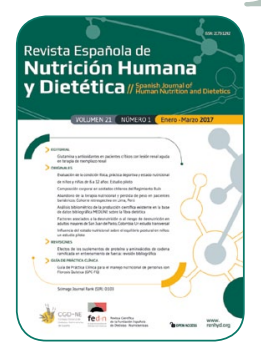

\title{
REVISIÓN
}

\section{Efectos de los suplementos de proteína y aminoácidos de cadena ramificada en entrenamiento de fuerza: revisión bibliográfica}

\author{
Jordi Rabassa-Blanco ${ }^{a}$, Imma Palma-Linares ${ }^{a, *}$

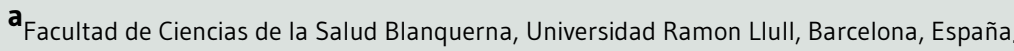 \\ *concepcionpl@blanquerna.edu
}

Recibido el 5 de marzo de 2016; aceptado el 20 de julio de 2016.

\section{PALABRAS CLAVE}

Aminoácidos

ramificados;

Proteína de suero;

Suplementos

dietéticos;

Entrenamiento de fuerza;

Fatiga;

Composición corporal.
Efectos de los suplementos de proteína y aminoácidos de cadena ramificada en entrenamiento de fuerza: revisión bibliográfica

\section{RESUMEN}

Introducción: Los suplementos de proteína y aminoácidos de cadena ramificada (BCAAs) son consumidos por la población buscando una serie de efectos fisiológicos y metabólicos sobre el rendimiento y recuperación, entre otros. Objetivo: Revisar las publicaciones más recientes que estudien los efectos del consumo de suplementos de proteína y BCAAs en entrenamiento de fuerza en diferentes parámetros fisiológicos y metabólicos.

Material y Métodos: Estudio descriptivo de revisión bibliográfica. Se realizó una búsqueda específica de palabras clave en la base de datos PubMed y estrategia de bola de nieve. Criterios de inclusión: estudios realizados en humanos de $\geq 18$ años sin patología, metaanálisis, revisiones sistemáticas y ensayos clínicos controlados aleatorizados en inglés y español relacionados con el consumo de suplementos de proteína y/o BCAAs en entrenamiento de fuerza y sus efectos sobre el daño muscular, respuesta anabólica en la recuperación muscular, ganancia de masa muscular y fuerza, composición corporal y fatiga.

Resultados: 64 estudios identificados mediante la ecuación de búsqueda, 20 cumplieron con los criterios de inclusión. La media aritmética de los sujetos participantes fue igual a $(30,59 \pm 24,47)$.

Conclusiones: Los suplementos de proteína podrían tener un efecto positivo en el aumento del rendimiento y la masa muscular, pero hacen falta más estudios para esclarecer su posible beneficio sobre la composición corporal, la fatiga, la atenuación y reducción del dolor y daño muscular. La leucina tiene efecto en el aumento de la masa muscular y su función en población de edad avanzada. Los BCAAs podrían actuar sobre la atenuación de la fatiga central y en la mejora del rendimiento. 
Effects of protein and branched-chain amino acids supplements in resistance training: a review

\section{KEYWORDS}

Amino Acids, Branched-Chain;

Whey Proteins;

Dietary

Supplements;

Resistance Training;

Fatigue;

Body Composition.

\section{ABSTRACT}

Introduction: The protein supplements and branched-chain amino acids (BCAAs) are consumed by all kinds of people to obtain a number of physiological and metabolic effects reversing improvements in performance and fast recovery among others. Objective: To perform an exhaustive review of the most recent scientific publications where it has studied the effects of consuming protein supplements and BCAAs in resistance training in different physiological and metabolic parameters.

Material and Methods: Descriptive literature review. A specific keyword search was conducted in the PubMed database and snowball strategy. Inclusion criteria: studies in humans of $\geq 18$ without pathology, meta-analysis, systematic reviews and randomized controlled trials in English and Spanish related to the consumption of protein supplements and/or BCAAs in resistance training and its effects on muscle damage, anabolic response in muscle recovery, gain muscle mass and strength, body composition and fatigue.

Results: Out of the 64 studies identified by the search equation, 20 met the inclusion criteria. The arithmetic mean of the participating subjects is equal to (30.59 \pm 24.47$)$.

Conclusions: Protein supplements may have a positive effect on increasing muscle mass and performance, but further studies are needed to clarify their potential benefit on body composition, fatigue, attenuation and reducing pain and muscle damage. Leucine has an effect on the increase of muscle mass and its function in the elderly. BCAAs could act on the attenuation of central fatigue and on performance improvement.

\section{CITA}

Rabassa-Blanco J, Palma-Linares I. Efectos de los suplementos de proteína y aminoácidos de cadena ramificada en entrenamiento de fuerza: revisión bibliográfica. Rev Esp Nutr Hum Diet. 2017; 21(1): 55-73. doi: 10.14306/ renhyd.21.1.220

\section{INTRODUCCIÓN}

Los suplementos de proteína y/o aminoácidos de cadena ramificada (BCAAs, por sus siglas en inglés) son consumidos por atletas, militares y, en general, por población activa que practica actividad física, ejercicio físico y/o deporte de forma recreacional1 ${ }^{1-9}$. La toma de polvos de proteínas u otros suplementos sin una garantía de calidad del producto, a pesar de poder producir un aumento de la masa muscular, mejora de la fuerza y en consecuencia del rendimiento, pueden suponer un riesgo para la salud ${ }^{3,7,9,10}$. Algunos de los motivos por los cuales se toman los suplementos nutricionales son para ayudar a la recuperación del entrenamiento, el mantenimiento o mejora de la salud, la mejora del rendimiento, mejorar funciones inmunes, tratar y prevenir una enfermedad $y / 0$ para compensar una dieta pobre en ingesta de energía $a^{1,2,4-6,8,11}$. De todos estos motivos, el consumo de productos de proteína está relacionado con aumentos de la masa muscular, así como promover la recuperación y regeneración muscular ${ }^{2,5}$.

Son muchas las fuentes por las cuales la población obtiene información y adquiere los suplementos nutricionales: familiares, amigos, publicidad (como revistas o medios online), compañeros de equipo y entrenadores ${ }^{1,3,7}$. Además de las mencionadas con anterioridad, los atletas profesionales acostumbran a obtener esta información por otras fuentes como nutricionistas, médicos, farmacéuticos o fisioterapeutas $\mathrm{s}^{1,2,4,5,8}$.

La información que puede obtener la población físicamente activa de forma recreacional respecto al uso de suplementos nutricionales es preocupante, ya que el uso de suplementos de proteína está muy extendido en los gimnasios, siendo la 
Efectos de los suplementos de proteína y aminoácidos de cadena ramificada en entrenamiento de fuerza: revisión bibliográfica

primera opción de consumo por los sujetos que acuden a estos centros ${ }^{12,13}$, seguido de los aminoácidos $(A A)^{12}$. Por lo tanto, el consumidor de productos nutricionales debería recibir un correcto y ético asesoramiento personal antes de su consumo.

Es importante destacar que no hay un consenso científico entre la administración de suplementos de proteína y los beneficios asociados a su rendimiento $0^{10,14,15}$. Son muchas las investigaciones que han estudiado los posibles efectos asociados a los suplementos de proteína y/o BCAAs en torno a la ganancia de masa muscular ${ }^{16-19}$, fuerza ${ }^{20,21}$, composición corporal de los sujetos ${ }^{20-22}$, atenuación de la fatiga ${ }^{23,24}$, reducción del dolor y daño muscular ${ }^{25-27}$ y el efecto de la respuesta anabólica mediante la activación de una serie de enzimas que permiten el aumento de la síntesis de proteínas $^{28-32}$.

También hay revisiones sistemáticas y metaanálisis que evalúan los efectos de los suplementos de proteína en la masa muscular y la fuerza ${ }^{33-35}$, si el momento de ingesta está relacionado con mejoras en la fuerza y masa muscular ${ }^{36}$, si los suplementos de proteína tienen efectos sobre el daño muscular y la recuperación de la función muscular ${ }^{37}$, así como cambios en la composición corporal en gente mayor ${ }^{38}$. Sin embargo, faltan datos más rigurosos y precisos sobre la respuesta anabólica y la fatiga central, así como qué protocolo de suplementación es más eficaz y seguro.

Debido a que teóricamente existe una participación de los suplementos de proteína y BCAAs en el metabolismo energético en entrenamiento de fuerza, cada vez son más los suplementos de nutrición deportiva que incorporan en su fórmula proteínas y/o BCAAs para incidir en los efectos anteriormente mencionados. Sin embargo, no se ha establecido una dosis y posología exacta ni sus efectos positivos en el individuo. La Agencia Europea de Seguridad Alimentaria (EFSA), en 2010, emitió un informe sobre las declaraciones nutricionales y de propiedades saludables relacionando los BCAAs con el crecimiento y mantenimiento de la masa muscular, atenuación de la disminución de la masa muscular en deportes de altitud, mayor rapidez de recuperación de la fatiga después del ejercicio, mejora de la función cognitiva después del ejercicio, reducción del esfuerzo percibido durante el ejercicio y sistema inmunitario saludable ${ }^{39}$. En base a esta opinión científica, a partir de los artículos presentados en el informe, se llega a la conclusión de que no se ha establecido una relación de causa-efecto entre el consumo de BCAAs y los parámetros fisiológicos mencionados ${ }^{39}$.

En el mismo año, la EFSA emitió otro informe sobre las declaraciones nutricionales y de propiedades saludables relacionando el consumo de proteína de suero con el aumento de la saciedad que conduce a una reducción en la ingesta de energía, la contribución al mantenimiento o consecución de un peso corporal normal, el crecimiento o mantenimiento de la masa muscular, el aumento de la masa magra durante la restricción de energía y entrenamiento de fuerza, la reducción de la masa grasa durante la restricción de energía y el entrenamiento de fuerza, el aumento de la fuerza muscular, la reparación del tejido muscular esquelético y la mayor rapidez de recuperación de la fatiga después del ejercicio ${ }^{40}$. En base a esta opinión científica se llega a la misma conclusión causa-efecto entre el consumo de suplementos de proteína de suero y los parámetros fisiológicos mencionados ${ }^{40}$.

Por lo tanto, debido al elevado consumo de estos suplementos entre la población deportista, el objetivo principal de este trabajo fue llevar a cabo una exhaustiva revisión de las publicaciones científicas más recientes, con el fin de identificar si en los últimos años se ha podido llegar a establecer una relación causa-efecto entre el consumo de suplementos de proteína de suero y/o BCAAs y los parámetros fisiológicos y metabólicos anteriormente mencionados, que justifique éste incremento en el consumo.

\section{MATERIAL Y MÉTODOS}

Estudio descriptivo de revisión bibliográfica sobre el estado actual del efecto del consumo de suplementos de proteína y BCAAs en relación al entrenamiento de fuerza. Se realizó una búsqueda estructurada en la base de datos PubMed, utilizando descriptores de Ciencias de la Salud (Medical Subjects Headings - MeSH), sinónimos de estos términos y palabras clave que tuvieran relación con la cuestión del estudio. De este modo, la ecuación de búsqueda que se aplicó, fue la siguiente:

((((Protein[tiab] OR "Proteins"[Mesh] OR "Proteins"[tiab] OR "Whey Protein"[tiab] OR "Whey Proteins"[tiab] OR "Protein Synthesis"[tiab] OR "Protein Diet"[tiab] OR "Dietary Proteins"[Mesh] OR "Dietary Proteins"[tiab] OR "Dietary Protein"[tiab] OR "Protein Intake"[tiab] OR "Protein Supplementation"[tiab] OR "Protein Supplements"[tiab] OR "Protein Supplement"[tiab] OR "Whey Casein"[tiab] OR "Casein Whey"[tiab] OR "Whey Protein Isolate"[tiab] OR "Whey Protein Hydrolysate"[tiab] OR "Whey Protein Concentrate"[tiab]) AND ("Amino Acids, Branched-Chain"[Mesh] OR "Branched-Chain Amino Acids"[tiab] OR "Branched-Chain Amino Acid"[tiab] OR "Branch Chain Amino Acids"[tiab] OR Isoleucine[Mesh] OR Isoleucine[tiab] OR "L-Isoleucine"[tiab] OR Leucine[Mesh] OR Leucine[tiab] OR "L-Leucine"[tiab] OR Valine[Mesh] OR Valine [tiab] OR "L-Valine"[tiab] OR "Branched-Chain Amino Acids 
Efectos de los suplementos de proteína y aminoácidos de cadena ramificada en entrenamiento de fuerza: revisión bibliográfica

Supplementation"[tiab])) AND ("Resistance Training"[Mesh] OR "Resistance Training"[tiab] OR "Strength Training"[tiab] OR "Resistance Exercise"[tiab] OR "Exercise Training"[tiab] OR "Muscle Training"[tiab] OR "Training Muscle"[tiab] OR "Training Weight"[tiab] OR "Weight Lifting"[Mesh] OR "Weight Lifting"[tiab] OR "Intensity Interval Training"[tiab] OR "High Intensity Interval Training"[tiab])) AND (("randomized controlled trial"[pt] $\mathrm{OR}$ "controlled clinical trial"[pt] OR randomized[tiab] OR placebo[tiab] OR "clinical trials as topic"[MeSH Terms:noexp] OR randomly[tiab] OR trial[ti]) OR ("Meta-Analysis" [Publication Type] OR "Meta-Analysis as Topic"[Mesh] OR "Meta-Analysis"[tiab]) OR (systematic[sb] OR (systematic[tiab] AND review[tiab]))) NOT ("animals"[MeSH Terms] NOT ("humans"[MeSH Terms] AND "animals"[MeSH Terms])).

Esta ecuación de búsqueda fue utilizada para desarrollar los resultados del estudio. Además, para la posterior discusión se obtuvieron artículos referentes a la materia aplicando la estrategia de bola de nieve.

Los términos siguientes fueron eliminados de la ecuación de búsqueda inicial por no ser encontrados por la base de datos PubMed: "Protein Whey"[tiab], "Whey Protein Muscle"[tiab], "Whey Protein Side Effects"[tiab], "Whey Protein Muscle Growth"[tiab], "Amino Acids, Branched-Chain"[tiab], "Acids, Branched-Chain Amino"[tiab], "Branched-Chain Amino Acids Muscle"[tiab], "Weight Liftings"[tiab], "Proteins supplements"[tiab], "Proteins supplement"[tiab].

Los artículos seleccionados para la revisión bibliográfica debían cumplir los siguientes criterios de inclusión:

- Publicaciones en hombres y/o mujeres de $\geq 18$ años de edad que fueran deportistas-no deportistas, amateurs-profesionales, entrenados-no entrenados, sedentarios-no sedentarios; sin patología metabólica, pulmonar, cardiovascular, renal y/o hepática.

- Metaanálisis, revisiones sistemáticas y ensayos clínicos controlados y aleatorizados relacionados con el consumo de BCAAs (leucina, isoleucina y valina) y proteína (suero de leche) en entrenamiento de fuerza y sus efectos sobre el daño muscular, la respuesta anabólica en la recuperación muscular, el aumento de masa muscular, la ganancia de fuerza-potencia muscular, la composición corporal y la fatiga central y/o periférica.

- Se incluyeron estudios que trataran trabajos de cualquier manifestación de la fuerza y se analizaron publicaciones con proteína de suero de leche y BCAAs; a pesar de ello, para la comparación de los estudios experimentales y la debida obtención de sus efectos se permitieron las mezclas de proteína, otros tipos de proteína que no fuese la de suero de leche, otros aminoácidos esenciales (AAEs) y la proteína/BCAAs con hidratos de carbono $(\mathrm{HC})$.

- Publicaciones de los últimos 5 años.

- Publicaciones en inglés y español.

- Estudios publicados en cualquier país.

Se excluyeron todos los estudios que no cumplían con los criterios de inclusión previamente determinados. No obstante, en la discusión se permitieron otros estudios que no fuesen metaanálisis, revisiones sistemáticas y ensayos clínicos controlados y aleatorizados.

Tampoco se tuvieron en cuenta los efectos de otras ayudas ergogénicas precursoras de los BCAAs como, por ejemplo, el metabolito de la leucina $\beta$-hidroxi- $\beta$-metilbutirato (HMB). También se excluyó la interacción de cualquier otra ayuda ergogénica con las proteínas y/o los BCAAs.

Selección de los estudios: Se planteó el diseño de un protocolo de recogida de datos que agrupaba las investigaciones según el efecto del consumo de suplementos de proteína y/o BCAAs en entrenamiento de fuerza: daño muscular, respuesta anabólica, ganancia de masa muscular, ganancia de fuerza, composición corporal y fatiga.

A continuación, se realizó un cribaje de los estudios. En primer lugar, se realizó una primera criba donde sólo se tuvo en cuenta el título y resumen de los estudios. En caso de duda se dejaba la selección, o no, de la publicación dudosa para el segundo cribaje. En esta segunda criba, para poder añadir el estudio dentro de los resultados se tuvieron en cuenta los criterios de inclusión y exclusión de la tabla PICOT ${ }^{41}$. Todas las publicaciones del segundo cribaje, tanto si eran inclusivas como exclusivas, se documentaron en formato tabla. En esta segunda criba y partiendo de la ecuación de búsqueda sólo se tuvieron en cuenta los estudios desde 2011 hasta agosto de 2015, ambos incluidos.

El protocolo de recogida de datos estaba compuesto por las siguientes variables:

- Estudio: autor/es-autora/as y año de publicación.

- Muestra: número de sujetos que participan en cada publicación y sexo. Especificando si son activos-no activos o entrenados-no entrenados.

- Protocolo de suplementación: se especificaba la dosis, la pauta de administración y la duración de la suplementación.

- Protocolo de entrenamiento: plan de ejercicios, duración del entrenamiento y parámetros de carga establecidos en cada ejercicio para estudiar el efecto de los 
suplementos de proteína y/o BCAAs, antes, durante y/o después del entrenamiento.

- Efectos/resultados: principales resultados relacionados con el daño muscular, respuesta anabólica, aumento de masa muscular, ganancia de fuerza (rendimiento deportivo), composición corporal y fatiga central y/o periférica.

Aspectos éticos: Todos los estudios analizados cumplían con los principios éticos de la Declaración de Helsinki de la Asociación Médica Mundial para las investigaciones en seres humanos.

\section{RESULTADOS}

Mediante la ecuación de búsqueda se identificaron 64 publicaciones en la literatura actual del tema, 23 de las cuales fueron eliminadas en la primera criba. En el segundo cribaje se analizaron 24 publicaciones, de las cuales 20 cumplían con los criterios de inclusión y 4 no. Dentro de esta criba hubo una publicación que no pudo ser incluida y revisada por no ser posible la accesibilidad a ella, a pesar de pedirla a la correspondencia del autor. El resto de las 16 publicaciones de la ecuación de búsqueda no se analizaron por razones de antigüedad, ya que a partir de los 5 años desde su publicación se considera un estudio antiguo.

Las Tablas 1-6 describen las variables utilizadas para estudiar los efectos de los suplementos de proteína y/o BCAAs en entrenamiento de fuerza. Estas tablas se dividieron en 5 secciones y muestran las publicaciones incluidas en la revisión. Las variables utilizadas fueron: estudio, muestra, protocolo de suplementación, protocolo de entrenamiento y efectos/resultados.

La media aritmética de sujetos participantes en los estudios fue igual a $(30,59 \pm 24,47)$. De los 19 estudios (sin contar con

Tabla 1. Efectos de los suplementos de proteína y/o BCAAs en la composición corporal.

\begin{tabular}{|c|c|c|c|c|}
\hline Estudio & $\begin{array}{c}\text { Muestra } \\
\text { Número/Sexo/NAF }\end{array}$ & $\begin{array}{l}\text { Protocolo de } \\
\text { suplementación }\end{array}$ & $\begin{array}{l}\text { Protocolo de } \\
\text { entrenamiento }\end{array}$ & Efectos/Resultados \\
\hline $\begin{array}{l}\text { Babault y Cols. } \\
(2014)^{23}\end{array}$ & $\begin{array}{l}68 \\
\text { Varones } \\
\text { activos }\end{array}$ & $\begin{array}{l}\text { Grupo PLA = 30g de HC. } \\
\text { Grupo MC (caseína)= 30g. } \\
\text { Grupo SMP (aislado de } \\
\text { PS)= 30g. } \\
2 \text { veces/día los días de no } \\
\text { entreno (mañana y tarde) } \\
\text { y } 3 \text { veces/día los días } \\
\text { de entreno (mañana, } 30 \\
\text { minutos antes y después } \\
\text { de entrenar). }\end{array}$ & $\begin{array}{l}3 \text { sesiones/semana durante } \\
10 \text { semanas. } \\
\text { Ejercicios: ER, PP y FR. } \\
\text { Semana 1-7: series } \uparrow \text { de } 3 \text { a } 5 \\
\text { y las reps. de } 8 \text { a } 15 \text {. } \\
\text { Semana } 8 \text { y } 9: 4 \text { series de } \\
20 \text { reps. } \\
\text { Semana } 10: 5 \text { series de } 6 \\
\text { reps. } \\
\text { Descanso entre series } 1-2 \\
\text { minutos. }\end{array}$ & $\begin{array}{l}\text { Sin diferencias significativas } \\
\text { entre grupos respecto la MC, } \\
\text { el \% MG o \% de MLG. }\end{array}$ \\
\hline $\begin{array}{l}\text { Herda y Cols. } \\
(2013)^{42}\end{array}$ & $\begin{array}{l}106 \\
\text { Varones } \\
\text { activos }\end{array}$ & $\begin{array}{l}3 \text { grupos con diferentes } \\
\text { tipos de PS y volumen de } \\
\text { entreno, un PLA y un CON. } \\
20 \mathrm{~g} \text { PS + 7g Leu o 20g PS. } \\
\text { PLA= 20g MD. CON= nada. } \\
1 \text { batido/día los días de no } \\
\text { entreno. } \\
2 \text { batidos/día los días } \\
\text { de entreno ( } 30 \text { minutos } \\
\text { antes e inmediatamente } \\
\text { después). }\end{array}$ & $\begin{array}{l}3 \text { días/semana durante } 8 \\
\text { semanas. } \\
\text { Ejercicios: PB y PP al } 80 \% \text { del } \\
\text { 1RM. } \\
\text { Grupo baja intens.: semana } \\
\text { 1, } 1 \text { serie de } 6 \text { reps; semana } \\
\text { 2, } 2 \times 6 \text {; semanas } 3-8,3 \times 6 \text {. } \\
\text { Otros grupos: semana } 1,3 \times 6 \text {; } \\
\text { semana } 2,4 \times 6 \text {; semanas } \\
3-8,5 \times 6 \text {. } \\
\text { Descanso de } 2 \text { minutos entre } \\
\text { series. }\end{array}$ & $\begin{array}{l}\text { Sin diferencias e interac- } \\
\text { ciones significativas entre } \\
\text { grupos para las variables } \\
\text { de CC. } \\
\text { Sin embargo, hubo un efecto } \\
\text { principal significativo debido } \\
\text { al entrenamiento para todas } \\
\text { las variables de CC (\% de MG, } \\
\% \text { de MM, \% de MC y CSA del } \\
\text { muslo). }\end{array}$ \\
\hline
\end{tabular}




\begin{tabular}{|c|c|c|c|c|}
\hline Estudio & Muestra & $\begin{array}{l}\text { Protocolo de } \\
\text { suplementación }\end{array}$ & $\begin{array}{l}\text { Protocolo de } \\
\text { entrenamiento }\end{array}$ & Efectos/Resultados \\
\hline $\begin{array}{l}\text { Volek y Cols. } \\
(2013)^{22}\end{array}$ & $\begin{array}{l}63 \\
\text { Varones y Mujeres } \\
\text { no entrenados/as }\end{array}$ & $\begin{array}{l}\text { Grupo CARB= MD. } \\
\text { Grupo WHEY= } \approx 22 \mathrm{~g} / \mathrm{d} \\
\text { concentrado de PS. } \\
\text { Grupo SOY= } \approx 22 \mathrm{~g} / \mathrm{d} \text { aisla- } \\
\text { do de proteína de soja. } \\
1 \text { batido/día: días de no } \\
\text { entreno por la mañana, } \\
\text { días de entreno inme- } \\
\text { diatamente después del } \\
\text { ejercicio. }\end{array}$ & $\begin{array}{l}12 \text { semanas de programa, } \\
96 \text { sesiones ( } \approx 9 \text { meses). } \\
4 \text { estilos de entreno: suave } \\
\text { (12-15 reps., } 60-90 \text { segundos } \\
\text { descanso, intens. ligera); } \\
\text { medio (8-10 reps., intens. } \\
\text { moderada); pesado (3-6 } \\
\text { reps., } 2-3 \text { minutos descanso, } \\
\text { alta intens.); potencia (ejer- } \\
\text { cicios de todo el cuerpo al } \\
30-45 \% \text { del } 1 \text { RM, } 3 \text { minutos } \\
\text { descanso). } \\
\text { 3-5 series/ejercicio y diferen- } \\
\text { tes ejercicios. }\end{array}$ & $\begin{array}{l}\text { MC y MM } \uparrow \text { significativa- } \\
\text { mente a los } 3 \text { meses y se } \\
\text { mantiene significativamente } \\
\text { más alta que la línea de base } \\
\text { a los } 6 \text { y } 9 \text { meses para todos } \\
\text { los grupos. } \\
\text { Sin diferencias entre grupos } \\
\text { en el } \uparrow \text { de MC. } \\
\text { MM } \uparrow \text { en el grupo WHEY } \\
\text { en comparación a los otros } \\
\text { grupos. } \\
\text { Sin diferencias significativas } \\
\text { en la pérdida de MG entre } \\
\text { grupos. }\end{array}$ \\
\hline
\end{tabular}

NAF: nivel de actividad física; PLA: placebo; HC: hidratos de carbono, entreno: entrenamiento; ER: extensión de rodillas (leg extension); PP: prensa de piernas (leg press); FR: flexión de rodillas; reps.: repeticiones; MC: masa corporal; MG: masa grasa;

MGL: masa libre de grasa; PS: proteína de suero; CON: control; Leu: leucina; MD: maltodextrina; PB: press de banca;

CC: composición corporal; MM: masa magra/muscular; CSA: área de sección transversal; intens.: intensidad;

$$
\uparrow \text { : aumento/a; RM: repetición máxima. }
$$

Tabla 2. Efectos de los suplementos de proteína y/o BCAAs en la masa muscular.

\begin{tabular}{|c|c|c|c|c|}
\hline Estudio & $\begin{array}{l}\text { Muestra } \\
\text { Número/Sexo/NAF }\end{array}$ & $\begin{array}{l}\text { Protocolo de } \\
\text { suplementación }\end{array}$ & $\begin{array}{l}\text { Protocolo de } \\
\text { entrenamiento }\end{array}$ & Efectos/Resultados \\
\hline $\begin{array}{l}\text { Cruz-Jentoft y } \\
\text { Cols. }(2014)^{43}\end{array}$ & $\begin{array}{l}\text { Valoración de } 7 \\
\text { estudios de mode- } \\
\text { rada a alta calidad } \\
\text { sobre intervención } \\
\text { nutricional en } \\
\text { población de } \geq 50 \\
\text { años con sarcope- } \\
\text { nia. }\end{array}$ & & & $\begin{array}{l}\leftrightarrow \text { suplementos de proteína } \\
\text { en la MM y su función. } \\
\text { Suplementos de AAEs, } \\
\text { incluyendo } 2,5-2,8 \mathrm{~g} \text { de Leu, } \\
\text { muestran algunos efectos en } \\
\text { la mejora de los parámetros } \\
\text { de MM y su función. }\end{array}$ \\
\hline $\begin{array}{l}\text { Farup y Cols. } \\
(2014)^{19}\end{array}$ & $\begin{array}{l}22 \\
\text { Varones } \\
\text { activos }\end{array}$ & $\begin{array}{l}\text { Grupo WHD = 19,5g de PS } \\
\text { hidrolizada alta en Leu }+ \\
19,5 \mathrm{~g} \text { de HC (glucosa). } \\
\text { Grupo PLA= } 39 \mathrm{~g} \text { de HC } \\
\text { solos. } \\
30 \text { minutos antes y des- } \\
\text { pués del entrenamiento. }\end{array}$ & $\begin{array}{l}3 \text { veces/semana durante } \\
12 \text { semanas ( } 33 \text { sesiones en } \\
\text { total). } \\
\text { Ejercicio: ERM con una } \\
\text { pierna. Fase concéntrica con } \\
\text { una pierna, fase excéntrica } \\
\text { con la otra. } \\
\text { Protocolo de series y reps.: } \\
\text { 6x10-15RM (sesiones 1-4), } \\
8 \times 10-15 R M \text { (sesiones 5-10), } \\
\text { 10x10-15RM (sesiones } \\
\text { 11-20), 12x6-10RM (sesiones } \\
21-28 \text { ) y } 8 \times 6-10 \text { (sesiones } \\
29-33) .2 \text { segundos de } \\
\text { ejecución en ambas fases. } \\
\text { Descanso de } 2 \text { minutos entre } \\
\text { series. }\end{array}$ & $\begin{array}{l}\text { Sin diferencias en el modo de } \\
\text { contracción. } \\
\text { CSA del cuádriceps } \uparrow 7,3 \% \\
\text { en WHD y } 3,4 \% \text { en el PLA. El } \\
\text { CSA del tendón rotuliano } \uparrow \\
14,9 \% \text { en WHD y } 8,1 \% \text { en el } \\
\text { PLA. Por lo tanto, un mayor } \\
\text { aumento del grupo WHD en } \\
\text { comparación al PLA. } \\
\text { No hay correlación entre los } \\
\text { cambios del CSA del cuádri- } \\
\text { ceps y del tendón rotuliano. }\end{array}$ \\
\hline
\end{tabular}

NAF: nivel de actividad física; PLA: placebo; HC: hidratos de carbono; ERM: extensión de rodillas en máquina; reps.: repeticiones;

PS: proteína de suero; Leu: leucina; MM: masa magra/muscular; AAEs: aminoácidos esenciales;

CSA: área de sección transversal; RM: repetición máxima; $\uparrow:$ aumento/a; $\leftrightarrow:$ sin efecto adicional. 
Tabla 3. Efectos de los suplementos de proteína y/o BCAAs en la fatiga central y/o periférica.

\begin{tabular}{|c|c|c|c|c|}
\hline Estudio & $\begin{array}{c}\text { Muestra } \\
\text { Número/Sexo/NAF }\end{array}$ & $\begin{array}{l}\text { Protocolo de } \\
\text { suplementación }\end{array}$ & $\begin{array}{l}\text { Protocolo de } \\
\text { entrenamiento }\end{array}$ & Efectos/Resultados \\
\hline $\begin{array}{l}\text { Babault y Cols. } \\
(2014)^{23}\end{array}$ & $\begin{array}{l}68 \\
\text { Varones } \\
\text { activos }\end{array}$ & $\begin{array}{l}\text { Grupo PLA = 30g de HC. } \\
\text { Grupo MC (caseína)= 30g. } \\
\text { Grupo SMP (aislado de } \\
\text { PS)=30g. } \\
2 \text { veces/día los días de no } \\
\text { entreno (mañana y tarde) } \\
\text { y } 3 \text { veces/día los días } \\
\text { de entreno (mañana, } 30 \\
\text { minutos antes y después } \\
\text { de entrenar). }\end{array}$ & $\begin{array}{l}3 \text { sesiones/semana durante } \\
10 \text { semanas. } \\
\text { Ejercicios: ER, PP y FR. } \\
\text { Semana } 1-7 \text {, series } \uparrow \text { de } 3 \text { a } \\
5 \text { y las reps. de } 8 \text { a } 15 . \\
\text { Semana } 8 \text { y 9, } 4 \text { series de } \\
20 \text { reps. } \\
\text { Semana } 10,5 \text { series de } 6 \\
\text { reps. } \\
\text { Descanso entre series } 1-2 \\
\text { minutos. }\end{array}$ & $\begin{array}{l}\text { La fatiga muscular } \downarrow \text { signifi- } \\
\text { cativamente en el grupo SMP } \\
\text { después de } 4 \text { y } 10 \text { semanas } \\
\text { de entreno en comparación al } \\
\text { grupo PLA y MC. } \\
\text { La fatiga muscular en } \\
\text { preejercicio y postejercicio } \downarrow \\
\text { significativamente en el grupo } \\
\text { SMP, mientras } \uparrow \text { en el grupo } \\
\text { MC y PLA. }\end{array}$ \\
\hline
\end{tabular}

NAF: nivel de actividad física; PLA: placebo; HC: hidratos de carbono; PS: proteína de suero; entreno: entrenamiento;

ER: extensión de rodillas (leg extension); PP: prensa de piernas (leg press); FR: flexión de rodillas; reps.: repeticiones; $\uparrow$ : aumento/a; $\downarrow$ : disminuye.

Tabla 4. Efectos de los suplementos de proteína y/o BCAAs en la fuerza muscular (rendimiento deportivo).

\begin{tabular}{|c|c|c|c|c|}
\hline Estudio & $\begin{array}{c}\text { Muestra } \\
\text { Número/Sexo/NAF }\end{array}$ & $\begin{array}{l}\text { Protocolo de } \\
\text { suplementación }\end{array}$ & $\begin{array}{l}\text { Protocolo de } \\
\text { entrenamiento }\end{array}$ & Efectos/Resultados \\
\hline $\begin{array}{l}\text { Boone y Cols. } \\
(2015)^{44}\end{array}$ & $\begin{array}{l}18 \\
\text { Varones } \\
\text { no entrenados }\end{array}$ & $\begin{array}{l}\text { Grupo PRO=17g de } \\
\text { concentrado de PS + } 3 \mathrm{~g} \text { de } \\
\text { calostro bovino + 3g Leu } \\
\text { Grupo PLA= 20g de MD. } \\
1 \text { batido/día inmedia- } \\
\text { tamente después de la } \\
\text { sesión en los días de } \\
\text { entreno. }\end{array}$ & $\begin{array}{l}3 \text { sesiones/semana durante } \\
4 \text { semanas. } \\
\text { Ejercicios: CM] unilateral, PP } \\
\text { (LP) y ER (LE) con la pierna } \\
\text { dominante. } \\
3 \text { series de } 8 \text { reps. al máximo } \\
\text { esfuerzo. } \\
\text { Ejercicios de PP y ER, } 3 \times 8-10 \\
\text { al } 80 \% 1 \text { RM. } 90 \text { segundos } \\
\text { de descanso entre series y } \\
\text { ejercicios. }\end{array}$ & $\begin{array}{l}\text { Valoración de: espesor (MT), } \\
\text { ángulo de penación y área } \\
\text { de sección transversal (CSA) } \\
\text { del recto femoral (RF) y del } \\
\text { vasto lateral (VL) de la pierna } \\
\text { dominante. } \\
\uparrow \text { significativo en el LP, LE, } \\
\text { MVIC (máxima fuerza iso- } \\
\text { métrica), RF MT, CSA RF, VL } \\
\text { MT y VL CSA. Sin diferencias } \\
\text { significativas entre grupos. } \\
\leftrightarrow \text { suplementos de proteína } \\
\text { postejercicio. EF a c/p } \\
\uparrow \text { fuerza y tamaño muscular } \\
\text { en varones no entrenados } \\
\text { previamente. }\end{array}$ \\
\hline $\begin{array}{l}\text { Babault y Cols. } \\
(2014)^{23}\end{array}$ & $\begin{array}{l}68 \\
\text { Varones } \\
\text { activos }\end{array}$ & $\begin{array}{l}\text { Grupo PLA = 30g de HC. } \\
\text { Grupo MC (caseína)= 30g. } \\
\text { Grupo SMP (aislado de } \\
\text { PS)= 30g. } \\
2 \text { veces/día los días de no } \\
\text { entreno (mañana y tarde) } \\
\text { y } 3 \text { veces/día los días } \\
\text { de entreno (mañana, } 30 \\
\text { minutos antes y después } \\
\text { de entrenar). }\end{array}$ & $\begin{array}{l}3 \text { sesiones/semana durante } \\
10 \text { semanas. } \\
\text { Ejercicios: ER, PP y FR. } \\
\text { Máximas reps. posibles de } \\
\text { los ejercicios de PP y FR al } \\
80 \% \text { del } 1 \text { RM, para calcular } \\
\text { la resistencia muscular. }\end{array}$ & $\begin{array}{l}\text { Sin diferencias significativas } \\
\text { entre grupos en la resistencia } \\
\text { muscular, GM (aunque } \uparrow \text { sig- } \\
\text { nificativamente con el tiempo } \\
\text { en los grupos), MPM, FM y PE. }\end{array}$ \\
\hline
\end{tabular}




\begin{tabular}{|c|c|c|c|c|}
\hline Estudio & $\frac{\text { Muestra }}{\text { Número/Sexo/NAF }}$ & $\begin{array}{c}\text { Protocolo de } \\
\text { suplementación }\end{array}$ & $\begin{array}{l}\text { Protocolo de } \\
\text { entrenamiento }\end{array}$ & Efectos/Resultados \\
\hline $\begin{array}{l}\text { Herda y Cols. } \\
(2013)^{42}\end{array}$ & $\begin{array}{l}106 \\
\text { Varones } \\
\text { activos }\end{array}$ & $\begin{array}{l}3 \text { grupos con diferentes } \\
\text { tipos de PS ( } 20 \mathrm{~g} \text { PS }+7 \mathrm{~g} \\
\text { Leu o } 20 \mathrm{~g} \text { PS) y volumen } \\
\text { de entreno, un PLA (= } 20 \mathrm{~g} \\
\text { MD) y un CON (= nada) } \\
1 \text { batido/día los días de } \\
\text { no entreno, } 2 \text { batidos/día } \\
\text { los días de entreno ( } 30 \\
\text { minutos antes e inmedia- } \\
\text { tamente después). }\end{array}$ & $\begin{array}{l}3 \text { días/semana durante } 8 \\
\text { semanas. } \\
\text { Ejercicios: PB y PP al } 80 \% \text { del } \\
\text { 1RM. } \\
\text { Grupo baja intensidad: } \\
\text { semana 1, } 1 \text { serie de } 6 \text { reps.; } \\
\text { semana 2, } 2 \times 6 \text {; semanas } \\
\text { 3-8, } 3 \times 6 \text {. } \\
\text { Otros grupos: semana } 1,3 \times 6 ; \\
\text { semana } 2,4 \times 6 \text {; semanas } \\
3-8,5 \times 6 . \\
\text { Descanso de } 2 \text { minutos entre } \\
\text { series. }\end{array}$ & $\begin{array}{l}\text { Sin diferencias e interac- } \\
\text { ciones significativas entre } \\
\text { grupos para las variables de } \\
\text { rendimiento muscular (FM } \\
\text { y VRM). } \\
\text { Debido al entreno, efecto } \\
\text { principal en las variables de } \\
\text { rendimiento muscular (PBM, } \\
\text { PBR, PPM y PPR). }\end{array}$ \\
\hline
\end{tabular}

NAF: nivel de actividad física; PS: proteína de suero; Leu: leucina; MD: maltodextrina; entreno: entrenamiento;

CMJ: counter movement jump; PP: prensa de piernas (leg press); ER: extensión de rodillas (leg extension); reps.: repeticiones;

RM: repetición máxima; EF: entrenamiento de fuerza; c/p: a corto plazo; máx.: máximas; FR: flexión de rodillas;

GM: grosor muscular; MPM: máxima potencia muscular; FM: fuerza muscular; PE: percepción del esfuerzo; PLA: placebo;

CON: control; PB: press de banca; VRM: variables de resistencia muscular; PBM: press de banca máximo; PBR: press de banca repeticiones; PPM: prensa de piernas máximo; PPR: prensa de piernas repeticiones; $\uparrow:$ aumento/a; $\leftrightarrow$ : sin efecto adicional.

Tabla 5. Efectos de los suplementos de proteína y/o BCAAs en el daño muscular.

\begin{tabular}{|c|c|c|c|c|}
\hline Estudio & $\begin{array}{c}\text { Muestra } \\
\text { Número/Sexo/NAF }\end{array}$ & $\begin{array}{l}\text { Protocolo de } \\
\text { suplementación }\end{array}$ & $\begin{array}{l}\text { Protocolo de } \\
\text { entrenamiento }\end{array}$ & Efectos/Resultados \\
\hline $\begin{array}{l}\text { Kirby y Cols. } \\
(2012)^{45}\end{array}$ & $\begin{array}{l}27 \\
\text { Varones }\end{array}$ & $\begin{array}{l}\text { Grupo LEU= } 250 \mathrm{mg} / \mathrm{kg} \\
\text { PC de Leu/dosis. } \\
\text { Grupo PLA = 3g de edulco- } \\
\text { rante no calórico/dosis. } \\
\text { Grupo CON = sin suple. y } \\
\text { entreno. } \\
30 \text { minutos antes del } \\
\text { ejercicio, inmediatamente } \\
\text { preejercicio, inmediata- } \\
\text { mente postejercicio, e } \\
\text { inmediatamente antes de } \\
\text { cada sesión postest ( } 24, \\
48,72 \text { y } 96 \text { horas). }\end{array}$ & $\begin{array}{l}\text { Sesión de test } 1: 3 \mathrm{SI}+3 \mathrm{SV} \text {. } \\
\text { Mismo test: } 24,48,72 \text { y } 96 \\
\text { horas después. } 3 \text { minutos de } \\
\text { descanso entre intentos. } \\
\text { Sesión de test } 2: 5 \text { series de } \\
20 \text { D] desde } 60 \mathrm{~cm} \text { de altura, } \\
10 \text { segundos de descanso } \\
\text { entre saltos y } 2 \text { minutos } \\
\text { entre series }+6 \text { series de } \\
10 \text { reps. en la PP (CE) al } \\
120 \% \text { del } 1 \text { RM, } 3 \text { minutos } \\
\text { de descanso entre series. } 3 \\
\text { segundos de ejecución en la } \\
\text { fase excéntrica. }\end{array}$ & $\begin{array}{l}\text { Sin diferencias significati- } \\
\text { vas entre los grupos en los } \\
\text { marcadores bioquímicos } \\
\text { (CK y Mb) de daño muscular } \\
\text { después de EEF. } \\
\text { La Leu puede ayudar al man- } \\
\text { tenimiento de producción de } \\
\text { Fl. Grupo LEU } \uparrow \text { significativa- } \\
\text { mente vs. el PLA después de } \\
\text { la sesión de ejercicio. } \\
\text { El dolor muscular } \uparrow \text { signi- } \\
\text { ficativamente después del } \\
\text { ejercicio a las } 24,48,72 \text { y } \\
96 \text { horas en los grupos LEU } \\
\text { y PLA. Grupo LEU tuvo un } \uparrow \\
\text { significativamente mayor en } \\
\text { la media de dolor muscular } \\
\text { vs. el PLA. }\end{array}$ \\
\hline
\end{tabular}




\begin{tabular}{|c|c|c|c|c|}
\hline Estudio & $\begin{array}{l}\text { Muestra } \\
\text { Número/Sexo/NAF }\end{array}$ & $\begin{array}{l}\text { Protocolo de } \\
\text { suplementación }\end{array}$ & $\begin{array}{l}\text { Protocolo de } \\
\text { entrenamiento }\end{array}$ & Efectos/Resultados \\
\hline $\begin{array}{l}\text { Howatson y } \\
\text { Cols. }(2012)^{27}\end{array}$ & $\begin{array}{l}12 \\
\text { Varones } \\
\text { entrenados }\end{array}$ & $\begin{array}{l}12 \text { días de protocolo (7 } \\
\text { días de fase de carga, día } \\
8 \text { realización protocolo de } \\
\text { entreno). } \\
\text { Grupo BCAA=10g de } \\
\text { BCAAs, } 2 \text { veces/día (ma- } \\
\text { ñana y tarde). Ratio 2:1:1 } \\
\text { de Leu, Val e lle. } \\
\text { Grupo PLA= edulcorante } \\
\text { artificial. } \\
+20 \mathrm{~g} \text { de suple. } 1 \text { hora } \\
\text { antes del ejercicio e inme- } \\
\text { diatamente postejercicio. }\end{array}$ & $\begin{array}{l}5 \text { series de } 20 \text { DJ desde } \\
\text { una altura de } 60 \mathrm{~cm} \text { con } 10 \\
\text { segundos de descanso entre } \\
\text { saltos y } 2 \text { minutos entre se- } \\
\text { ries + } 3 \mathrm{CMJ} \text { con descanso de } \\
60 \text { segundos entre saltos. } \\
3 \text { reps. isométricas de } \\
3 \text { segundos cada una en el } \\
\text { ejercicio de ER (pierna domi- } \\
\text { nante) con descanso de } 60 \\
\text { segundos entre reps. }\end{array}$ & $\begin{array}{l}\text { La CK } \downarrow \text { significativamente } \\
\text { en el grupo BCAA vs. PLA. } \\
\text { Pico de daño de CK a las } \\
24 \text { postejercicio en ambos } \\
\text { grupos. } \\
\text { Pico de dolor muscular a las } \\
48 \text { postejercicio en ambos } \\
\text { grupos. Pero éste } \downarrow \text { signifi- } \\
\text { cativamente a las } 24 \text { y } 48 \\
\text { horas postejercicio en el } \\
\text { grupo BCAA vs. PLA. } \\
\text { MVC era mayor en el grupo } \\
\text { BCAA. }\end{array}$ \\
\hline
\end{tabular}

NAF: nivel de actividad física; PLA: placebo; CON: control; PC: peso corporal; suple.: suplementación; entreno: entrenamiento;

SI: sentadillas isométricas; SV: saltos verticales; DJ: drop jumps; reps.: repeticiones; CE: contracción excéntrica;

PP: prensa de piernas (leg press); CK: creatina quinasa; Mb: mioglobina; EEF: ejercicio excéntrico de fuerza; FI: fuerza isométrica; BCAAs: aminoácidos ramificados; Leu: Leucina; Val: valina; lle: isoleucina; CMJ: counter movement jump; ER: extensión de rodilla

(leg extension); MVC: máxima contracción isométrica; RM: repetición máxima; $\uparrow:$ aumento/a; $\downarrow$ : disminuye.

Tabla 6. Efectos de los suplementos de proteína y/o BCAAs sobre la respuesta anabólica en la recuperación muscular.

\begin{tabular}{|c|c|c|c|c|}
\hline Estudio & $\begin{array}{l}\text { Muestra } \\
\text { Número/Sexo/NAF }\end{array}$ & $\begin{array}{l}\text { Protocolo de } \\
\text { suplementación }\end{array}$ & $\begin{array}{l}\text { Protocolo de } \\
\text { entrenamiento }\end{array}$ & Efectos/Resultados \\
\hline $\begin{array}{l}\text { D'Souza y Cols. } \\
(2014)^{30}\end{array}$ & $\begin{array}{l}46 \\
\text { Varones } \\
\text { no entrenados }\end{array}$ & $\begin{array}{l}\text { Grupo PLA= bebida no } \\
\text { calórica. } \\
\text { Grupos EXP=10g, } 20 \mathrm{~g} \text {, } \\
30 \mathrm{~g} \text { y } 40 \mathrm{~g} \text { de concentrado } \\
\text { de suero. } \\
\text { Ingesta: inmediatamente } \\
\text { después del ejercicio. }\end{array}$ & $\begin{array}{l}\text { Circuito de } 3 \text { ejercicios. } 3 \\
\text { series de } 8-10 \text { reps. al } 80 \% \\
\text { del 1RM. } \\
\text { Ejercicios: SMS, PP y ER. } 1 \\
\text { minuto de descanso entre } \\
\text { ejercicios y } 3 \text { minutos entre } \\
\text { series (vuelta al circuito). }\end{array}$ & $\begin{array}{l}\text { Fosforilación p70S6K } \uparrow \\
\text { significativamente } 2 \text { horas } \\
\text { postejercicio en los grupos } \\
\text { que reciben } \geq 20 \mathrm{~g} \text { de PS. }\end{array}$ \\
\hline $\begin{array}{l}\text { Ferreira y Cols. } \\
(2014)^{46}\end{array}$ & $\begin{array}{l}27 \\
\text { Varones } \\
\text { activos }\end{array}$ & $\begin{array}{l}\text { Grupo PLA= bebida con } \\
\text { sabor. } \\
\text { Grupo } \mathrm{HC}=1,5 \mathrm{~g} / \mathrm{kg} \text { de } \\
\mathrm{MM}(\approx 120 \mathrm{~g} / \text { participante) } \\
\text { de } \mathrm{HC} \text {. } \\
\text { Grupo } \mathrm{HC}+\mathrm{BCAA}=\text { ratio } 2: 1: 1 \\
\text { Leu, lle y Val, } \\
\approx 60 \mathrm{mg} / \mathrm{kg} \text { Leu }(\approx 5 \mathrm{~g}), \\
30 \mathrm{mg} / \mathrm{kg} \text { lle y } 30 \mathrm{mg} / \mathrm{kg} \\
\text { Val (total= } 120 \mathrm{mg} / \mathrm{kg} \text { de MM } \\
\text { de BCAAs) }+\mathrm{HC} \text { (proporción } \\
\text { grupo HC). } \\
\text { Momento de ingesta } \\
\text { (150ml/dosis): en ayunas, } \\
10 \text { minutos antes del ejer- } \\
\text { cicio y } 5 \text { minutos después } \\
\text { del ejercicio. }\end{array}$ & $\begin{array}{l}1 \text { sesión. } 4 \text { series de } 8-12 \\
\text { reps. al } 75-80 \% \text { del } 1 \text { RM en } \\
\text { la } \mathrm{PP}+4 \text { series de } 8-12 \text { reps. } \\
\text { al } 75-80 \% \text { del } 1 \text { RM en la } \\
\text { máquina de } E R \text {. } \\
2,5 \text { minutos de descanso } \\
\text { entre series y ejercicios. }\end{array}$ & $\begin{array}{l}\text { Sin diferencias en el } \uparrow \text { de la } \\
\text { PI3K/Akt-mTORC1, antes y } \\
\text { después del entreno, entre } \\
\text { los grupos HC y HC + BCAA. } \\
\text { Akt y mTORC1 } \uparrow \text { significati- } \\
\text { vamente a las } 0,5 \text { y } 2 \text { horas } \\
\text { postejercicio, p70S6K a las } 6 \\
\text { horas postejercicio. } \\
\text { Sin diferencias de aumen- } \\
\text { tos entre los tres grupos. } \\
\text { EF depende del } \uparrow \text { de estos } \\
\text { marcadores. Así, el } \uparrow \text { de } \\
\text { la mTORC1, Akt y p70S6K } \\
\text { puede exhibir un } \uparrow \text { postejer- } \\
\text { cicio, independientemente } \\
\text { de suplementar con BCAAs } \\
\text { y/o HC. } \\
\text { Sin efectos significativos en } \\
\text { la } 4 \text { EBP1. }\end{array}$ \\
\hline
\end{tabular}




\begin{tabular}{|c|c|c|c|c|}
\hline Estudio & $\begin{array}{l}\text { Muestra } \\
\text { Número/Sexo/NAF }\end{array}$ & $\begin{array}{l}\text { Protocolo de } \\
\text { suplementación }\end{array}$ & $\begin{array}{l}\text { Protocolo de } \\
\text { entrenamiento }\end{array}$ & Efectos/Resultados \\
\hline $\begin{array}{l}\text { Churchward- } \\
\text { Venne y Cols. } \\
(2014)^{31}\end{array}$ & $\begin{array}{l}40 \\
\text { Varones } \\
\text { activos }\end{array}$ & $\begin{array}{l}\text { Grupo W6= 6,25g de PS } \\
\text { (0,75g Leu). } \\
\text { Grupo W6+Low-LEU= } \\
\text { 6,25g de PS (3g Leu). } \\
\text { Grupo W6+High-LEU= } \\
\text { 6,25g de PS (5g Leu). } \\
\text { Grupo W6+BCAA=6,25g } \\
\text { de PS con Ile, Val y Leu } \\
\text { (5g). } \\
\text { Grupo W25= 25g de PS } \\
\text { (3g Leu). } \\
\text { Ingesta: inmediatamente } \\
\text { después del ejercicio. }\end{array}$ & $\begin{array}{l}1 \text { sesión. } 8 \text { series de } 10-12 \\
\text { reps. al } 80 \% \text { del } 1 \text { RM. } \\
2 \text { minutos de descanso entre } \\
\text { series. } \\
\text { Ejercicio: ER en máquina } \\
\text { (unilateralmente). }\end{array}$ & $\begin{array}{l}\text { Añadir una dosis mayor de } \\
\text { Leu }(5 \mathrm{~g}) \text { con una baja toma } \\
\text { de PS }(6,25 \mathrm{~g}) \text { puede ser igual } \\
\text { de eficaz que tomar una } \\
\text { dosis alta de PS }(25 \mathrm{~g}) \text { para } \\
\text { estimular el } \uparrow \text { de la SPM. } \\
\uparrow \text { SPM, sin diferencias entre } \\
\text { grupos entre las } 0-1,5 \text { horas. } \\
\text { SPM } \uparrow \text { entre las } 1,5-4,5 \text { ho- } \\
\text { ras en los grupos W6+High- } \\
\text { LEU y W25. }\end{array}$ \\
\hline
\end{tabular}

NAF: nivel de actividad física; PLA: placebo; EXP: Experimentales; reps.: repeticiones; RM: repetición máxima; SMS: sentadilla en máquina Smith; PP: prensa de piernas (leg press); ER: extensión de rodillas (leg extension); $\uparrow:$ aumento/a;

HC: hidratos de carbono; MM: masa magra/muscular; BCAAs: aminoácidos ramificados; Leu: leucina; Ile: isoleucina; Val: valina; entreno: entrenamiento; EF: entrenamiento de fuerza; PS: proteína de suero; SPM: síntesis de proteínas musculares.

uno, que es revisión sistemática) sólo 4 incluyeron un grupo de mujeres. De éstos, 3 mezclaban hombres y mujeres y sólo uno tenía como muestra específica a mujeres. Los otros 15 estaban exclusivamente formados por varones.

Se describió el protocolo de suplementación teniendo en cuenta dos variables: dosis y posología. En la variable dosis se tuvieron en cuenta las cantidades ingeridas de cada suplemento, las concentraciones en gramos (g), miligramos (mg) o tanto por ciento (\%) de proteína, BCAAs y en su defecto de AAEs. Referente a la posología se analizó en qué momento se tomaba el suplemento durante el día, principalmente: antes de entrenar, durante el entrenamiento y después de entrenar. También se especificó cuánto duraba en el tiempo el consumo del suplemento.

En el protocolo de entrenamiento se tuvieron en cuenta las siguientes variables: frecuencia del programa de entrenamiento y/o sesión/es, ejercicio/s a realizar, tipología de contracción y parámetros de carga del entrenamiento (intensidad, volumen y descanso). Básicamente los ejercicios analizados en los estudios eran: extensión de rodilla/pierna $(n=14)$ y prensa de piernas $(n=10)$. No obstante, los otros ejercicios evaluados en los protocolos de entrenamiento de las publicaciones, eran los siguientes: press de banca $(n=1)$, flexión de rodilla/pierna $(n=1)$, ejercicios de todo el cuerpo $(n=1)$, sentadilla $(n=2)$ y otros ejercicios (squat jump, drop jump y/o counter movement jump) $(\mathrm{n}=3)$.

Los efectos de la suplementación con proteína y/o BCAAs se describieron para la composición corporal $(n=3)$, fatiga central y/o periférica $(n=1)$, ganancia de fuerza $(n=3)$, aumento de masa muscular $(n=2)$, daño muscular $(n=2)$ y respuesta anabólica en la recuperación muscular $(n=12)$. En esta última variable sólo se valoraron una serie de quinasas que influyen en la respuesta anabólica muscular, sin entrar a valorar expresiones de genes y expresiones de transportadores de aminoácidos. Sólo se mostraron en su tabla correspondiente aquellos 3 artículos con mayor número de muestra.

En la Tabla 7 se muestran las cuarto publicaciones que fueron excluidas en la segunda criba por no cumplir con los criterios de inclusión. 
Tabla 7. Artículos excluidos en la segunda criba.

\begin{tabular}{|c|c|c|c|}
\hline Autor/es & Año & Cita & Motivo de exclusión \\
\hline Reidy y Cols. & 2014 & $\begin{array}{l}\text { Reidy PT, Walker DK, Dickinson JM, Gundermann } \\
\text { DM, Drummond MJ, Timmerman KL, et al. Soy- } \\
\text { dairy protein blend and whey protein ingestion } \\
\text { after resistance exercise increases amino acid } \\
\text { transport and transporter expression in human } \\
\text { skeletal muscle. J Appl Physiol (1985). 2014; } \\
\text { 116(11): } 1353-64 \text {. }\end{array}$ & No se ajusta a los outcomes de la tabla PICOT. \\
\hline Luiking y Cols. & 2014 & $\begin{array}{l}\text { Luiking YC, Deutz NE, Memelink RG, Verlaan S, } \\
\text { Wolfe RR. Postprandial muscle protein synthesis } \\
\text { is higher after a high whey protein, leucine-enri- } \\
\text { ched supplement than after a dairy-like product } \\
\text { in healthy older people: a randomized controlled } \\
\text { trial. Nutr J. 2014; 13: } 9 \text {. }\end{array}$ & $\begin{array}{l}\text { No se ajusta a los outcomes de la tabla PICOT. EI } \\
\text { diseño de estudio no aporta datos objetivos sobre } \\
\text { los efectos a nivel de incremento de fuerza mus- } \\
\text { cular, aumento de masa magra u otros outcomes. }\end{array}$ \\
\hline $\begin{array}{l}\text { Ormsbee y } \\
\text { Cols. }\end{array}$ & 2012 & $\begin{array}{l}\text { Ormsbee MJ, Mandler WK, Thomas DD, Ward EG, } \\
\text { Kinsey AW, Simonavice E, et al. The effects of six } \\
\text { weeks of supplementation with multi-ingredient } \\
\text { performance supplements and resistance trai- } \\
\text { ning on anabolic hormones, body composition, } \\
\text { strength, and power in resistance-trained men. J } \\
\text { Int Soc Sports Nutr. 2012; } 9(1): 49 \text {. }\end{array}$ & $\begin{array}{l}\text { No se ajusta a la "I" (Intervención) de la tabla } \\
\text { PICOT. En el suplemento intervienen otros ayudas } \\
\text { ergogénicas: beta-alanina, creatina y cafeína. Por } \\
\text { lo tanto, los efectos pueden verse involucrados } \\
\text { por estas substancias o la interacción de los } \\
\text { diferentes compuestos del suplemento. }\end{array}$ \\
\hline Kumar y Cols. & 2012 & $\begin{array}{l}\text { Kumar V, Atherton PJ, Selby A, Rankin D, Wi- } \\
\text { Iliams J, Smith K, et al. Muscle protein synthetic } \\
\text { responses to exercise: effects of age, volume, } \\
\text { and intensity. J Gerontol A Biol Sci Med Sci. } \\
\text { 2012; 67(11): 1170-7. }\end{array}$ & $\begin{array}{l}\text { El estudio se excluyó por falta de una "I" (inter- } \\
\text { vención), es decir, un grupo experimental que } \\
\text { tome proteína de suero y/o BCAAs, ya que sólo } \\
\text { compara el grupo de jóvenes vs. mayores y el } \\
\text { efecto del entrenamiento, pero sin el efecto de un } \\
\text { suplemento nutricional. }\end{array}$ \\
\hline
\end{tabular}

\section{DISCUSIÓN}

Debido a que las investigaciones valoran diversos efectos de los suplementos de proteína y/o BCAAs en entrenamiento de fuerza, éstos, se analizan por separado.

Efectos en la composición corporal: En las últimas investigaciones realizadas respecto a los efectos de los suplementos de proteína sobre la mejora de la composición corporal, porcentaje de masa grasa y porcentaje de masa libre de grasa, parece ser que no hay diferencias significativas entre la mejora de estos parámetros y la ingesta de estos suplementos $^{23,42}$. Los estudios de Verdijk y Cols. ${ }^{47}$ y Herda y Cols. ${ }^{42}$ muestran efectos significativos debido al entrenamiento de fuerza para las variables de composición corporal (porcentaje de masa grasa, porcentaje de masa magra y porcentaje de masa corporal total). Volek y Cols. ${ }^{22}$ también observaron una ligera reducción de la masa grasa a los 3 meses del programa, que se mantuvo durante toda la investigación (9 meses), pero sin diferencias entre los grupos de proteína y el grupo de HC. Por lo tanto, probablemente esta reducción se deba al entrenamiento.

No obstante, los resultados del estudio de Volek y Cols. muestran mejoras en la ganancia de masa magra con un suplemento de $\approx 22 \mathrm{~g} / \mathrm{d}$ de concentrado de proteína de suero de leche en comparación a otros tipos de proteínas, además de correlacionar elevaciones de leucina en ayunas con cambios en la masa magra ${ }^{22}$. Otro estudio mostró aumentos significativos en las variables de masa corporal, masa libre de grasa y masa del muslo después de 10 semanas de entrenamiento de fuerza, tanto en el grupo que tomaba proteínas como en el grupo placebo, sin embargo, los incrementos en el grupo de proteínas eran mayores que el placebo ${ }^{20}$. En el estudio de Wilborn y Cols. ${ }^{21}$, en mujeres universitarias y jugadoras de baloncesto, después de un programa de 8 semanas de entrenamiento de fuerza, agilidad y acondicionamiento físico, se muestra que con el consumo de $24 \mathrm{~g}$ de proteína de suero o caseína, antes y después del ejercicio, 
Efectos de los suplementos de proteína y aminoácidos de cadena ramificada en entrenamiento de fuerza: revisión bibliográfica

disminuye la masa grasa y aumenta la masa magra; pero sin comprobar con un grupo control si estas diferencias se deben al entrenamiento o a los suplementos.

En su metaanálisis, Komar y Cols. indican que la suplementación con leucina en sujetos de $\geq 65$ años ejerce efectos beneficiosos sobre el peso corporal, el índice de masa corporal (IMC) o la masa magra38.

Efectos en la masa muscular: En población de edad avanzada con sarcopenia, Cruz-Jentoft y Cols. concluyen que los suplementos de AAEs, incluyendo $\approx 2,5-3 \mathrm{~g}$ de leucina, muestran algunos efectos en la mejora de los parámetros de masa muscular y su función ${ }^{43}$. Un dato relevante a tener en cuenta, a pesar de la exclusión de la publicación por falta de una intervención en el análisis de los resultados, es que en población de edad avanzada el volumen de entrenamiento puede ser clave para obtener un aumento de la respuesta muscular al ejercicio ${ }^{48}$.

En el estudio de Farup y Cols. ${ }^{19}$ muestran que después de 12 semanas de entrenamiento y el consumo de un suplemento de proteína de suero de leche alto en leucina $(\approx 20 \mathrm{~g})$ más HC $(\approx 20 \mathrm{~g})$, antes y después del entrenamiento, aumenta el área de sección transversal del músculo cuádriceps en comparación al grupo placebo. En la misma línea se encuentra la investigación de Hulmi y Cols. ${ }^{17}$, donde exponen que después de 21 semanas de entrenamiento ( 2 veces/semana) y un suplemento de proteína de suero de leche $(15 \mathrm{~g})$, inmediatamente antes y después de cada sesión de ejercicio, provoca un adicional aumento de la hipertrofia del vasto externo en comparación al grupo placebo. Resultados similares a los anteriores son observados en el estudio de Hartman y Cols. ${ }^{18}$. Estos autores afirman que el consumo crónico de leche desnatada (500ml: $\approx 17,5 \mathrm{~g}$ de proteína, $\approx 27,5 \mathrm{~g} \mathrm{HC} \mathrm{y}$ $\approx 0,4$ grasas), inmediatamente y 1 hora después del entrenamiento de fuerza (durante 12 semanas, 5 días/semana) aporta mayores ganancias de masa magra y un aumento del área de las fibras tipo II en comparación a un grupo que toma proteína de soja (misma ratio de macronutrientes que la leche) y un placebo (maltodextrina). Andersen y Cols. ${ }^{16}$, después de 14 semanas de entrenamiento de fuerza (3 días/semana), también muestran una hipertrofia en las fibras musculares I y $l$ en el grupo con suplemento de proteínas ( $25 \mathrm{~g}$ de suero de leche, caseína, huevo blanco y glutamina) tomado inmediatamente antes y después del ejercicio, mientras que no indican cambios significativos en el grupo de HC ( $25 \mathrm{~g}$ de maltodextrina).

En una línea opuesta, Erskine y Cols. ${ }^{49}$ exponen que $20 \mathrm{~g}$ de proteína de suero de leche $(\approx 50 \%$ de AAEs) consumida inmediatamente antes y después del ejercicio no provoca diferencias significativas en el área de sección transversal del músculo bíceps en comparación a un placebo. En la investigación de Weisgarber y Cols. ${ }^{50}$ se han encontrado los mismos resultados que en el estudio anterior pero sin diferencias entre grupos a pesar de observar un aumento significativo de la masa muscular, después de 8 semanas de entrenamiento del tronco inferior (4 días/semana) y el consumo de $0,3 \mathrm{~g} / \mathrm{kg}$ de proteína de suero de leche o la misma cantidad de un suplemento isocalórico de $\mathrm{HC}$.

Schoenfeld y Cols. ${ }^{36}$, en su metaanálisis indican que el momento de ingesta tiene un efecto significativo sobre la hipertrofia muscular. Además, Pasiakos y Cols. ${ }^{33}$ indican que en individuos no entrenados (de 18 a 50 años) los cambios en la masa muscular durante las primeras semanas de entrenamiento de fuerza no son influenciados por la administración de proteínas (categoría de evidencia A). Sin embargo, también muestran que los incrementos en los parámetros de duración y frecuencia en un programa de entrenamiento de la fuerza, en individuos entrenados y no entrenados, juntamente con la ingesta de suplementos de proteína, promueven mayores ganancias en la masa muscular (categoría de evidencia $B)^{33}$. Además, también afirman que la adición de HC a los suplementos de proteína no promueven ningún cambio adicional en la masa magra durante un programa de entrenamiento de la fuerza (categoría de evidencia A), y que el tipo o combinaciones de varios tipos de suplementos de proteína afectan a la ganancia de la masa muscular a lo largo de un programa (categoría de evidencia $B)^{33}$.

En una línea parecida, pero en personas de $\geq 60$ años, Finger y Cols. ${ }^{34}$, en su metaanálisis indican que los suplementos de proteína no se asocian a un aumento de la masa muscular en comparación a grupos control que sólo son sometidos a entrenamiento de fuerza. Anteriormente estos resultados habían sido corroborados en otro metaanálisis, indicando que los suplementos de aminoácidos o proteínas no aumentan significativamente más las ganancias de masa magra que un placebo en población de $\geq 65$ años $^{35}$.

Fatiga central y periférica: Babault y Cols. indican que el consumo de $30 \mathrm{~g}$ de aislado de proteína de suero con un protocolo específico de administración hace disminuir significativamente la fatiga muscular ${ }^{23}$. Resultados similares se han mostrado con una ingesta aguda de proteínas, después de 4 sesiones de entrenamiento y una toma de $42 \mathrm{~g}$ de una mezcla de proteínas patentada (aislado de proteína de suero de leche, aislado de caseína y 250mg de BCAAs), ingeridas antes y después del ejercicio: los sujetos que tomaban el suplemento mostraban mejoras significativas en la recuperación del rendimiento, siendo capaces de realizar más repeticiones que el grupo placebo ${ }^{24}$. Sin embargo, en otro estudio similar no lograron encontrar ningún efecto significativo entre los grupos experimentales y control en la reducción de la fatiga ${ }^{51}$. 
Efectos de los suplementos de proteína y aminoácidos de cadena ramificada en entrenamiento de fuerza: revisión bibliográfica

Uno de los mecanismos más interesantes que explicaría la disminución de la fatiga es el consumo de BCAAs, ya que pueden actuar como un neurotransmisor per se. Su ingesta aumenta las concentraciones en plasma de este tipo de aminoácidos y previene el aumento de la ratio de triptófano libre/BCAAs y, por lo tanto, el transporte y absorción de triptófano dentro del cerebro. Esto reduciría la síntesis, la concentración y la liberación del neurotransmisor 5-hidroxitriptamina (5-HT), que está directamente relacionado con el desarrollo de la fatiga central y consecuentemente con la reducción del rendimiento ${ }^{52}$. Otra posible hipótesis que indican Newsholme y Col. ${ }^{53}$ como causa de la fatiga central es la disminución de la concentración de glucosa en sangre. Estos mismos autores también plantean como posibles causas de la fatiga periférica la disminución de los fosfatos de creatina, la disminución del glucógeno y el aumento del lactato $\left(\mathrm{H}^{+}\right)^{53}$.

Efectos en la fuerza muscular: Las últimas investigaciones realizadas sobre los efectos de los suplementos de proteína y/o BCAAs sobre la ganancia de fuerza, sugieren que la suplementación no ayuda a su mejora como tampoco a la mejora de otros parámetros relacionados con el rendimiento deportivo ${ }^{23,42,44}$. Aun así, sí que se observaban mejoras en el aumento de la fuerza, el tamaño muscular y otros aumentos en parámetros de rendimiento (como la resistencia muscular) debido al entrenamiento de la fuerza. De esta forma, es posible que los efectos por sí solos del entrenamiento, según lo observado en los grupos control y/o placebo, puedan enmascarar los posibles beneficios del suplemento de proteína y/o BCAAs. Sin embargo, Willoughby y Cols. ${ }^{20}$ mostraron que pasadas 10 semanas de un programa de entrenamiento de fuerza a alta intensidad, combinado con la ingesta de $20 \mathrm{~g}$ de proteína ( $14 \mathrm{~g}$ de suero de leche y caseína y $6 \mathrm{~g}$ de aminoácidos), 1 hora antes y después del ejercicio, es más eficaz que un suplemento placebo ( $20 \mathrm{~g}$ de dextrosa) en la mejora de la fuerza muscular y el rendimiento. Resultados similares se encuentran en la investigación de Wilborn y Cols. ${ }^{21}$ mostrando que los suplementos de proteína, tanto el suero de leche como la caseína, aportan ganancias en la fuerza muscular y mejoras en otros parámetros del rendimiento después de 8 semanas de entrenamiento (4 veces/semana) y la ingesta de proteínas (antes y después del ejercicio). Pero sin comprobar con un grupo control si estas diferencias se deben al entrenamiento o a los suplementos.

A la inversa, Verdijk y Cols. ${ }^{47}$ no indican diferencias en la fuerza muscular o cualquier otro parámetro de rendimiento deportivo entre el grupo que toma suplemento de proteína (2 tomas de $10 \mathrm{~g}$ de caseína, antes e inmediatamente después de la sesión) y el placebo (agua aromatizada), después de 12 semanas de entrenamiento de fuerza (3 sesiones/semana) en hombres saludables de edad avanzada y que consumen adecuadas cantidades de proteína diaria.
Tal y como ya se ha apuntado con anterioridad, probablemente los cambios en los parámetros de fuerza se deban a factores neurológicos que hacen incrementar la fuerza después de un programa de entrenamiento y no a los suplementos de proteína. Así, Folland y Col. ${ }^{54}$ indican que dentro de las 2 primeras semanas de entrenamiento ya surgen cambios neurológicos que pueden ser debidos al aprendizaje de la técnica de los ejercicios y a cambios en la coordinación intermuscular de músculos agonistas, antagonistas y sinergistas.

Schoenfeld y Cols. ${ }^{36}$ indican que el momento de ingesta no tiene un efecto significativo en la mejora de la fuerza muscular. Asimismo, Pasiakos y Cols. ${ }^{33}$ indican que en los individuos no entrenados (de 18 a 50 años) los cambios en la fuerza muscular durante las primeras semanas de entrenamiento de fuerza no son influenciados por la administración de proteínas (categoría de evidencia A). Sin embargo, estos autores también indican que los incrementos en los parámetros de duración y frecuencia durante un programa de entrenamiento de la fuerza, en individuos entrenados y no entrenados, juntamente con la ingesta de suplementos de proteína, promueven mayores ganancias en la fuerza muscular (categoría de evidencia B) ${ }^{33}$. Además, afirman que la adición de $\mathrm{HC}$ a los suplementos de proteína no promueve ningún cambio adicional en la fuerza muscular durante un programa de entrenamiento de la fuerza (categoría de evidencia A), y que el tipo o combinaciones de varios tipos de suplementos de proteína afectan a las ganancias de fuerza a lo largo de un programa (categoría de evidencia B) ${ }^{33}$.

En una línea parecida, pero en sujetos de $\geq 60$ años, en su metaanálisis, Finger y Cols. indican que los suplementos de proteína no se asocian a un aumento de la fuerza muscular en comparación a grupos control que sólo son sometidos a entrenamiento de fuerza ${ }^{34}$. Anteriormente estos resultados habían sido corroborados en otro metaanálisis, indicando que los suplementos de aminoácidos o proteínas no aumentan significativamente más las ganancias de fuerza muscular que un placebo en población de $\geq 65$ años $^{35}$.

Daño muscular: El estudio de Kirby y Cols. ${ }^{45}$ muestra que suplementar con una cantidad determinada de leucina y con una temporización específica no proporciona efectos protectores de atenuación en los marcadores bioquímicos de daño muscular (creatina quinasa [CK] y mioglobina [Mb]) después de realizar ejercicios excéntricos de fuerza, como tampoco evita que el dolor muscular en los grupos experimentales disminuya durante las 96 horas postejercicio. Siguiendo la misma línea, en otro estudio ${ }^{55}$ se han encontrado resultados similares, indicando que diferentes momentos de ingesta no proporcionan diferencias entre grupos. No obstante, presentan protocolos de suplementación y entrenamiento distintos. 
Efectos de los suplementos de proteína y aminoácidos de cadena ramificada en entrenamiento de fuerza: revisión bibliográfica

En cambio, Howatson y Cols. ${ }^{27}$ indican que después de la toma de un suplemento de $10 \mathrm{~g}$ de BCAAs el daño muscular y el dolor muscular a las 24 y 48 horas postejercicio disminuyen significativamente en comparación a un placebo. Otros estudios ${ }^{25,26}$ también exponen que la combinación de un suplemento de HC y proteínas, o la leche, reduce los marcadores indicativos de daño muscular (CK y Mb).

Estos resultados se pueden traducir en que el dolor muscular de aparición tardía, inmediatamente después y durante las primeras horas postejercicio, no produce ninguna diferencia en cualquier punto de tiempo ni grupo; por lo tanto, una posible suplementación podría no ser eficaz. Pero sí que puede haber un efecto positivo con ciertas ingestas de BCAAs (ratio 2:1:1; leucina, isoleucina y valina, respectivamente) para atenuar el dolor y daño muscular (CK y Mb), así como interferir positivamente en ciertos parámetros de rendimiento relacionados con la fuerza. De todos modos, diversos interrogantes quedan por determinar sobre la cantidad de leucina o BCAAs y temporización, teniendo en consideración que la máxima ingesta segura de leucina seria $550 \mathrm{mg} / \mathrm{kg} / \mathrm{d}$ $0 \approx 39 \mathrm{~g} / \mathrm{d}$, ya que mayores aumentos podrían suponer un riesgo para la salud ${ }^{56}$.

La revisión sistemática realizada en 2014 por Pasiakos y Cols. $^{37}$ muestra que hay poca relación entre el consumo de un suplemento de proteína y la recuperación de la función muscular, atenuación del dolor muscular y/o reducción de marcadores indicativos de daño muscular, independientemente de si este suplemento se toma sólo o con $\mathrm{HC}$ y antes, durante o después de una sesión aguda de entrenamiento de fuerza (categoría de evidencia A).

Respuesta anabólica en la recuperación muscular: Después del ejercicio, la ingesta de diferentes tipos de suplementos de proteína aumenta las tasas de síntesis de proteínas musculares (SPM), estimula el crecimiento del balance proteico neto y facilita la respuesta adaptativa del músculo al entrenamiento prolongado ${ }^{57,58}$. También se ha observado que la ingesta de suplementos de proteína, antes y durante el ejercicio prolongado, puede ser una estrategia eficaz para facilitar la SPM y mejorar la respuesta adaptativa del músculo esquelético ${ }^{57,59}$. Es a partir de aquí que se intenta dar respuesta a toda una serie de proteínas y enzimas que intervienen en la respuesta anabólica del músculo y que tienen una estrecha relación entre ellas. Así, Apró y Cols. ${ }^{28}$ y Dickinson y Cols. ${ }^{29}$ indican que la actividad de la quinasa ribosomal s6 (S6K1 ${ }^{\text {Thr389) }}$ ) aumenta notablemente con la ingesta de leucina sola o AAEs con leucina. Además, Reidy y Cols. ${ }^{60}$ añaden que con un suplemento de mezcla de proteínas la respuesta anabólica de esta quinasa se prolonga en el tiempo posingesta en comparación a la misma ingesta de proteína de suero de leche. Por lo tanto, según estos tres estudios, la presencia de leucina adquiere un rol relevante para la activación de la ribosomal s6 quinasa.

La fosforilación de la p70S6K (perteneciente a la proteína ribosomal S6) aumenta en todos los grupos experimentales después del ejercicio y la ingesta de proteínas y/o $\mathrm{BCAAs}^{30,32,61-63}$. Burke y Cols. ${ }^{61}$ indican que la toma en pequeñas cantidades del suplemento de proteína da mejores resultados en la respuesta muscular de esta quinasa que la ingestión del suplemento en una sola toma. Además, Reitelseder y Cols. $^{63}$ añaden que no hay diferencias entre tomar proteína de suero de leche o caseína; pero una posible variable que hay que tener en cuenta y que podría influir es el diseño del estudio, ya que sólo evalúan la SPM dejando de lado el balance proteico neto y la degradación de proteínas. Ferreira y Cols. ${ }^{46}$ también demuestran que la p7056K aumenta independientemente de suplementar con BCAAs más $\mathrm{HC}$ o HC solos. Por lo tanto, los HC podrían tener su rol en la función de esta u otras quinasas participes en la respuesta anabólica del músculo.

De este modo, una posible dosis y posología para activar eficazmente la p70S6K podría ser, de acuerdo con lo analizado en los distintos estudios, el consumo de $20-25 \mathrm{~g}$ de proteína de suero de leche alta en leucina ( $\approx 3-5 \mathrm{~g}$ de leucina) o AAEs ( $\approx 260 \mathrm{mg} / \mathrm{kg}$ de PC, de los cuales: $\approx 120 \mathrm{mg} / \mathrm{kg}$ de BCAAs con una ratio 2:1:1 de leucina, isoluecina y valina, respectivamente) y con preferencia de ingesta del suplemento después del ejercicio, pero sin descartar la posibilidad y eficacia del antes y durante. Además, otra posibilidad de temporización a tener muy en cuenta, es la ingesta de estos suplementos a dosis pequeñas antes, durante y después del ejercicio.

Respecto a la fosforilación de la Fosfoinositol 3-quinasa (PI3K) y Proteína Quinasa B (Akt), Ferreira y Cols. ${ }^{46}$ indican que estas quinasas aumentan después del ejercicio pero con independencia a una suplementación y sin diferencias entre BCAAs más HC o HC solos. En cambio, otros estudios ${ }^{60,62,63}$ muestran cómo la fosforilación de la Akt aumenta después del ejercicio y la ingesta de diferentes protocolos de suplementación con proteínas y BCAAs. Por lo tanto, con estas referencias actuales, se hace difícil especular, intuir y teorizar con dosis eficaces y seguras, posologías y tipo de proteínas y/o AAEs/BCAAs para activar óptimamente estas dos quinasas.

Vistas las quinasas anteriores y su rol como estimulantes de la síntesis proteica, hay que comentar que todas esas quinasas son precursoras y dependientes de la proteína compleja diana de rapamicina en células de mamíferos (mTORC1), principal vía de señalización de la SPM. Varios estudios indican que la suplementación con un protocolo específico de proteína, AAEs y/o BCAAs incrementa la 
Efectos de los suplementos de proteína y aminoácidos de cadena ramificada en entrenamiento de fuerza: revisión bibliográfica

respuesta anabólica de la mTORC1 en las primeras 5 horas postejercicio $25,26,31,33$. De esta forma, según los estudios actuales revisados, un posible protocolo de suplementación para maximizar la estimulación de la mTORC1 sería el consumo de unos $10 \mathrm{~g}$ de AAEs o $\approx 240 \mathrm{mg} / \mathrm{kg}$ de PC de AAEs que incluyan $\approx 3 \mathrm{~g}$ de leucina, o $20-25 \mathrm{~g}$ de proteína (con preferencia al suero de leche) con una composición de $\approx 10 \mathrm{~g}$ de AAEs y $\approx 3 \mathrm{~g}$ de leucina y tomando el suplemento después del ejercicio, pero sin descartar la posibilidad del antes y durante y su ingesta a pequeñas dosis (cada $\approx 15$-20 minutos).

Por otro lado, Ferreira y Cols. ${ }^{46}$ plantean la posibilidad de ingerir $120 \mathrm{mg} / \mathrm{kg}$ de MM de BCAAs con o sin HC. Sin embargo, hay que tener presente que a pesar de compartir una estructura molecular similar, la valina e isoleucina no modulan la fosforilación de ninguna quinasa en las células musculares, ya que la leucina es el único aminoácido esencial capaz de estimular la fosforilación de la mTORC1 y la proteína de factor 4 de iniciación eucariótica (4EBP1), además de potenciar la amplitud de señalización de la p70S6K1 sobre otros $\mathrm{AAEs}^{64}$.

Por lo tanto, el aminoácido esencial que realmente tiene un papel relevante en la estimulación anabólica es la leucina, y el acompañamiento de las dosis anteriores de proteínas y AAEs/BCAAs con $\mathrm{HC}$ es una posibilidad muy coherente, ya que estimulan la insulina y otros factores de crecimiento insulínicos (IGF-1 y IGF-2). Así, leucina e insulina son potentes anabolizantes del músculo esquelético que estimulan la SPM y mejoran la señalización de la mTORC1. Esto se puede observar en los estudios de Koopman y Cols. ${ }^{65}$ y Dreyer y Cols. ${ }^{66}$, que muestran que la ingesta de un suplemento de leucina y proteína con $\mathrm{HC}$ o AAEs enriquecidos con leucina más HC aumenta la SPM y mejoran el balance proteico neto durante la recuperación.

Una vez tratadas algunas de las quinasas responsables de las rutas metabólicas de señalización muscular, se muestra como la SPM aumenta en el postejercicio (durante las $\approx 5$ horas de recuperación), a pesar de protocolos de suplementación y entrenamiento distintos $29,31,46,60-63,67,68$. No obstante, Ferreira y Cols. ${ }^{46}$ muestran que el aumento de la actividad de la mTORC1, Akt y p70S6K puede exhibir un aumento postejercicio con independencia de la suplementación, es decir, sugieren que el entrenamiento de fuerza provoca el incremento de la actividad de esos marcadores indicativos de SPM. En esa misma línea va la investigación de Burd y Cols. ${ }^{67}$ que indican que el ejercicio por sí solo ya hace aumentar la SPM siendo aun mucho más aumentado con la ingesta de proteína de suero de leche o caseína. Además, Reidy y Cols. ${ }^{60}$ plantean la posibilidad de utilizar una mezcla de proteínas y así permitir que las tasas de SPM permanezcan aumentadas en el período de descanso tardío, y así, prolongar su beneficio. No obstante, Reitelseder y Cols. ${ }^{63}$ afirman que la SPM postejercicio aumenta por igual tanto con proteína de suero de leche como con caseína. En cambio, Burd y Cols. ${ }^{67}$ comentan que el aislado de proteína de suero de leche estimula las tasas de SPM con mayor grado que la caseína. Como se observa, hay un baile de dosis, posologías y tipos de proteínas que varían según el diseño de estudio.

Phillips y Col. ${ }^{69}$ y Phillips $^{70}$ indican que la dosis máxima por ingesta de proteína de alta calidad para estimular la SPM parece estar entre los $20-25 \mathrm{~g}$, además de que se debería consumir en el período temprano de recuperación (inmediatamente o entre las 2 horas postejercicio). Estos autores también indican que la leucina juega un papel importante en la recuperación de las proteínas musculares. No obstante, las nuevas tendencias e investigaciones indican que $5 \mathrm{~g}$ de leucina con una baja toma de proteínas $(6,25 \mathrm{~g})$, inmediatamente después del ejercicio, puede ser igual de eficaz que tomar dosis altas de proteína $(25 \mathrm{~g})$ para estimular el aumento de las tasas de SPM y conseguir los mismos resultados de anabolismo muscular ${ }^{31}$. De este modo, según el análisis de resultados, posiblemente, las nuevas y futuras investigaciones se tendrían que centrar en analizar y comprobar si concentraciones bajas en proteína $(\approx 6,25 \mathrm{~g})$ junto con dosis de unos $45 \mathrm{mg} / \mathrm{kg}$ a $60 \mathrm{mg} / \mathrm{kg}$ de leucina (unos $3-5 \mathrm{~g}$ ) o estos $3-5 \mathrm{~g}$ de leucina con $\approx 6-10 \mathrm{~g}$ de otros AAEs son idóneos para conseguir maximizar la SPM y fosforilar las quinasas responsables de las rutas metabólicas del anabolismo muscular; además de comprobar qué momentos de ingesta son más óptimos.

\section{Limitaciones de la investigación}

En esta revisión bibliográfica existen varias limitaciones que deben de tenerse en cuenta a la hora de sacar conclusiones. En primer lugar, considerar la diferencia de protocolos de entrenamiento, los cuales pueden hacer variar los efectos que se atribuyen en cualquiera de las variables analizadas.

En segundo lugar, mencionar la falta de uniformidad en los protocolos de suplementación. La variabilidad de los estudios incluidos en la investigación hace que sea difícil poder comparar y sacar conclusiones claras y precisas respecto la dosis y momento de ingesta que puede ser más eficaz.

En tercer lugar, se analizan y comparan trabajos cuya población de estudio es de diferentes edades, sexo y nivel de entrenamiento. Por lo tanto, los efectos que se les pueda atribuir a los participantes pueden variar entre sujetos. Aun así, se ha intentado llegar a un consenso en alguna de las variables analizadas, mediante revisiones sistemáticas y/o metaanálisis sobre la materia (teniendo en cuenta sus propias limitaciones). 
Efectos de los suplementos de proteína y aminoácidos de cadena ramificada en entrenamiento de fuerza: revisión bibliográfica

Y por último, un número reducido de la muestra y la falta de control de la dieta limitan la eficacia de varias de las investigaciones revisadas. Además, no todos los estudios miden los mismos marcadores de evaluación de las variables analizadas en relación al efecto de los suplementos de proteína y/o BCAAs.

\section{COnClusiones}

Los suplementos de proteína no tienen un efecto significativo en el aumento de la masa muscular y fuerza, aunque podrían tener un efecto positivo en el aumento del rendimiento y la masa muscular en individuos con ingesta dietética y entrenamiento adecuados, después de realizar entrenamiento de fuerza prolongado en el tiempo. La leucina sí tiene efecto sobre la masa muscular y su función en población de edad avanzada con sarcopenia. No hay suficientes estudios que esclarezcan si los suplementos proteicos tienen beneficios sobre la composición corporal; sin embargo, la leucina podría tener efectos positivos en ciertos parámetros corporales, tanto en población joven como mayor. Faltan pruebas que determinen el papel de los suplementos de proteína y/o BCAAs en la fatiga; no obstante, parece ser que los BCAAs, y más concretamente la leucina, tienen un rol importante en la atenuación de la fatiga central y consecuentemente en la mejora del rendimiento. Se requieren más estudios para determinar si la suplementación con BCAAs o leucina sola podría aportar efectos positivos en la disminución del dolor y daño muscular postejercicio, sin embargo, hay poca relación entre la atenuación y reducción del dolor y daño muscular con la ingesta de suplementos de proteína. El momento de ingesta de proteínas no tiene un efecto positivo en la mejora de la fuerza muscular, pero sí sobre la ganancia de masa muscular. Bajas tomas de proteína con $5 \mathrm{~g}$ de leucina, inmediatamente después del ejercicio, pueden ser igual de eficaces que dosis altas de proteína para estimular el aumento de las tasas de síntesis de proteínas musculares y conseguir los mismos resultados de anabolismo muscular. Se necesitan más estudios sobre tipos o combinaciones de proteínas más óptimas en la mejora de ciertos parámetros fisiológicos.

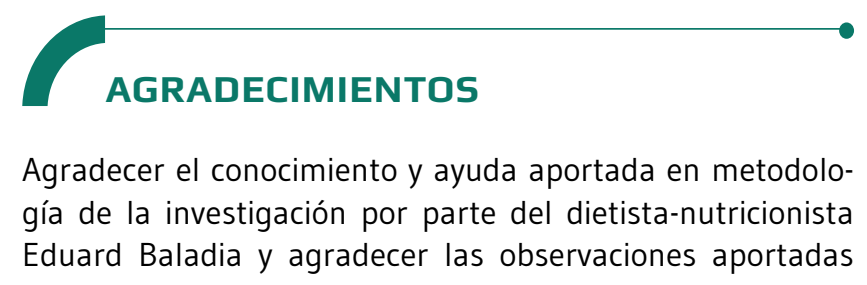

durante el trabajo por la Dra. María Antonia Lizarraga. Parte de los datos del presente manuscrito pertenecen al Trabajo Final de Máster en Nutrición de la Actividad Física y el Deporte de la Universidad de Barcelona.

\section{CONFLICTO DE INTERESES}

Los autores expresan que no hay conflictos de interés al redactar el manuscrito.

\section{$\longrightarrow$ \\ REFERENCIAS}

(1) Erdman KA, Fung TS, Reimer RA. Influence of Performance Level on Dietary Supplementation in Elite Canadian Athletes: Med Sci Sports Exerc. 2006; 38(2): 349-56.

(2) Maughan RJ, Depiesse F, Geyer H. The use of dietary supplements by athletes. J Sports Sci. 2007; 25(Suppl 1): S103-13.

(3) Petroczi A, Naughton DP. The age-gender-status profile of high performing athletes in the UK taking nutritional supplements: lessons for the future. J Int Soc Sports Nutr. 2008; 5: 2.

(4) Petróczi A, Naughton DP, Pearce G, Bailey R, Bloodworth A, McNamee $M$. Nutritional supplement use by elite young UK athletes: fallacies of advice regarding efficacy. J Int Soc Sports Nutr. 2008; 5: 22.

(5) Braun H, Koehler K, Geyer H, Kleiner J, Mester J, Schanzer W. Dietary supplement use among elite young German athletes. Int J Sport Nutr Exerc Metab. 2009; 19(1): 97-109.

(6) Tsitsimpikou C, Chrisostomou N, Papalexis P, Tsarouhas K, Tsatsakis A, Jamurtas $A$. The use of nutritional supplements among recreational athletes in Athens, Greece. Int ] Sport Nutr Exerc Metab. 2011; 21(5): 377-84.

(7) Pasiakos SM, Montain SJ, Young AJ. Protein supplementation in U.S. military personnel. J Nutr. 2013; 143(11): 1815S-9S.

(8) Aljaloud SO, Ibrahim SA. Use of Dietary Supplements among Professional Athletes in Saudi Arabia. J Nutr Metab. 2013; 2013: 1-7.

(9) Maughan RJ. Quality Assurance Issues in the Use of Dietary Supplements, with Special Reference to Protein Supplements. J Nutr. 2013; 143(11): 1843S-7S.

(10) Potgieter S. Sport nutrition: A review of the latest guidelines for exercise and sport nutrition from the American College of Sport Nutrition, the International Olympic Committee and the International Society for Sports Nutrition. S Afr ] Clin Nutr. 2013; 26(1): 6-16.

(11) Maughan RJ, Greenhaff PL, Hespel P. Dietary supplements for athletes: Emerging trends and recurring themes. J Sports Sci. 2011; 29(Suppl 1): S57-66.

(12) Rodríguez F, Crovetto M, González A, Morant N, Santibáñez F. Consumo de suplementos nutricionales en gimnasios, perfil del consumidor y características de su uso. Rev Chil Nutr. 2011; 38(2): 157-66. 
Efectos de los suplementos de proteína y aminoácidos de cadena ramificada en entrenamiento de fuerza: revisión bibliográfica

(13) Sánchez AJ, Miranda MT, Guerra E. Estudio estadístico del consumo de suplementos nutricionales y dietéticos en gimnasios. Arch Latinoam Nutr. 2008; 58(3): 221-7.

(14) Campbell B, Kreider RB, Ziegenfuss T, La Bounty P, Roberts M, Burke D, et al. International Society of Sports Nutrition position stand: protein and exercise. J Int Soc Sports Nutr. 2007; 4: 8.

(15) Position of the American Dietetic Association, Dietitians of Canada, and the American College of Sports Medicine: Nutrition and Athletic Performance. J Am Diet Assoc. 2009; 109(3): 509-27.

(16) Andersen LL, Tufekovic G, Zebis MK, Crameri RM, Verlaan G, Kjær $M$, et al. The effect of resistance training combined with timed ingestion of protein on muscle fiber size and muscle strength. Metabolism. 2005; 54(2): 151-6.

(17) Hulmi JJ, Kovanen V, Selänne, Kraemer WJ, Häkkinen K, Mero AA. Acute and long-term effects of resistance exercise with or without protein ingestion on muscle hypertrophy and gene expression. Amino Acids. 2009; 37(2): 297-308.

(18) Hartman JW, Tang JE, Wilkinson SB, Tarnopolsky MA, Lawrence $\mathrm{RL}$, Fullerton $A \mathrm{~V}$, et al. Consumption of fat-free fluid milk after resistance exercise promotes greater lean mass accretion than does consumption of soy or carbohydrate in young, novice, male weightlifters. Am J Clin Nutr. 2007; 86(2): 373-81.

(19) Farup J, Rahbek SK, Vendelbo MH, Matzon A, Hindhede J, Bejder $A$, et al. Whey protein hydrolysate augments tendon and muscle hypertrophy independent of resistance exercise contraction mode. Scand J Med Sci Sports. 2014; 24(5): 788-98.

(20) Willoughby DS, Stout JR, Wilborn CD. Effects of resistance training and protein plus amino acid supplementation on muscle anabolism, mass, and strength. Amino Acids. 2007; 32(4): 467-77.

(21) Wilborn CD, Taylor LW, Outlaw J, Williams L, Campbell B, Foster $C A$, et al. The Effects of Pre- and Post-Exercise Whey vs. Casein Protein Consumption on Body Composition and Performance Measures in Collegiate Female Athletes. J Sports Sci Med. 2013; 12(1): 74-9.

(22) Volek JS, Volk BM, Gómez AL, Kunces L, Kupchak BR, Freidenreich DJ, et al. Whey protein supplementation during resistance training augments lean body mass. J Am Coll Nutr. 2013; 32(2): 122-35.

(23) Babault N, Deley G, Le Ruyet P, Morgan F, Allaert FA. Effects of soluble milk protein or casein supplementation on muscle fatigue following resistance training program: a randomized, double-blind, and placebo-controlled study. J Int Soc Sports Nutr. 2014; 11: 36.

(24) Hoffman JR, Ratamess NA, Tranchina CP, Rashti SL, Kang J, Faigenbaum AD. Effect of a proprietary protein supplement on recovery indices following resistance exercise in strength/ power athletes. Amino Acids. 2010; 38(3): 771-8.

(25) Baty JJ, Hwang H, Ding Z, Bernard JR, Wang B, Kwon B, et al. The effect of a carbohydrate and protein supplement on resistance exercise performance, hormonal response, and muscle damage. J Strength. 2007; 21(2): 321-9.

(26) Cockburn E, Hayes PR, French DN, Stevenson E, St Clair Gibson A. Acute milk-based protein-CHO supplementation attenuates exercise-induced muscle damage. Appl Physiol Nutr Metab. 2008; 33(4): 775-83.

(27) Howatson G, Hoad M, Goodall S, Tallent J, Bell PG, French DN. Exercise-induced muscle damage is reduced in resistance- trained males by branched chain amino acids: a randomized, double-blind, placebo controlled study. J Int Soc Sports Nutr. 2012; 9: 20

(28) Apró W, Moberg M, Hamilton DL, Ekblom B, Rooyackers O, Holmberg $\mathrm{HC}$, et al. Leucine does not affect mechanistic target of rapamycin complex 1 assembly but is required for maximal ribosomal protein s6 kinase 1 activity in human skeletal muscle following resistance exercise. FASEB J. 2015; 29(10): 4358-73.

(29) Dickinson JM, Gundermann DM, Walker DK, Reidy PT, Borack MS, Drummond MJ, et al. Leucine-enriched amino acid ingestion after resistance exercise prolongs myofibrillar protein synthesis and amino acid transporter expression in older men. J Nutr. 2014; 144(11): 1694-702.

(30) D'Souza RF, Marworth JF, Figueiredo VC, Della Gatta PA, Petersen AC, Mitchell C], et al. Dose-dependent increases in p70S6K phosphorylation and intramuscular branched-chain amino acids in older men following resistance exercise and protein intake. Physiol Rep. 2014; 2(8): e12112.

(31) Churchward-Venne TA, Breen L, Di Donato DM, Hector AJ, Mitchell C], Moore DR, et al. Leucine supplementation of a lowprotein mixed macronutrient beverage enhances myofibrillar protein synthesis in young men: a double-blind, randomized trial. Am J Clin Nutr. 2014; 99(2): 276-86.

(32) Moberg M, Apró W, Ohlsson I, Pontén M, Villanueva A, Ekblom B, et al. Absence of leucine in an essential amino acid supplement reduces activation of $\mathrm{mTORC1}$ signalling following resistance exercise in young females. Appl Physiol Nutr Metab. 2014; 39(2): 183-94.

(33) Pasiakos SM, McLellan TM, Lieberman HR. The effects of protein supplements on muscle mass, strength, and aerobic and anaerobic power in healthy adults: a systematic review. Sports Med. 2015; 45(1): 111-31.

(34) Finger D, Goltz FR, Umpierre D, Meyer E, Rosa LHT, Schneider CD. Effects of protein supplementation in older adults undergoing resistance training: a systematic review and metaanalysis. Sports Med. 2015; 45(2): 245-55.

(35) Xu ZR, Tan ZJ, Zhang Q, Gui QF, Yang YM. Clinical effectiveness of protein and amino acid supplementation on building muscle mass in elderly people: a meta-analysis. PloS One. 2014; 9(9): e109141.

(36) Schoenfeld BJ, Aragon AA, Krieger JW. The effect of protein timing on muscle strength and hypertrophy: a meta-analysis. ] Int Soc Sports Nutr. 2013; 10(1): 53.

(37) Pasiakos SM, Lieberman HR, McLellan TM. Effects of protein supplements on muscle damage, soreness and recovery of muscle function and physical performance: a systematic review. Sports Med. 2014; 44(5): 655-70.

(38) Komar B, Schwingshackl L, Hoffmann G. Effects of leucinerich protein supplements on anthropometric parameter and muscle strength in the elderly: a systematic review and metaanalysis. J Nutr Health Aging. 2015; 19(4): 437-46.

(39) EFSA Panel on Dietetic Products N and A (NDA). Scientific Opinion on the substantiation of health claims related to branched-chain amino acids (BCAA) and growth or maintenance of muscle mass (ID 442, 444, 445, 447, 448, $451,1478)$, attenuation of the decline in muscle power following exercise at high altitude (ID 443), faster recovery from muscle fatigue after exercise (ID 447, 448, 684,1478), 
Efectos de los suplementos de proteína y aminoácidos de cadena ramificada en entrenamiento de fuerza: revisión bibliográfica

improvement of cognitive function after exercise (ID 446) reduction in perceived exertion during exercise (ID 450) and «healthy immune system» (ID 449) pursuant to Article 13(1) of Regulation (EC) No 1924/2006. EFSA J. 2010; 8(10): 1790.

(40) EFSA Panel on Dietetic Products, Nutrition and Allergies (NDA). Scientific Opinion on the substantiation of health claims related to whey protein and increase in satiety leading to a reduction in energy intake (ID 425), contribution to the maintenance or achievement of a normal body weight (ID 1683), growth or maintenance of muscle mass (ID 418, 419, 423, 426, 427, 429, 4307), increase in lean body mass during energy restriction and resistance training (ID 421), reduction of body fat mass during energy restriction and resistance training (ID 420, 421), increase in muscle strength (ID 422, 429), increase in endurance capacity during the subsequent exercise bout after strenuous exercise (ID 428), skeletal muscle tissue repair (ID 428 ) and faster recovery from muscle fatigue after exercise (ID $423,428,431$ ), pursuant to Article $13(1)$ of Regulation (EC) No 1924/2006. EFSA J. 2010; 8(10): 1818.

(41) Cochrane Collaboration. Unit Five: Asking an Answerable Question [portal en internet]. Cochrane Collaboration [citado 26 Ago 2015]. Disponible en: http://ph.cochrane.org/sites/ ph.cochrane.org/files/uploads/Unit_Five.pdf

(42) Herda AA, Herda TJ, Costa PB, Ryan ED, Stout JR, Cramer JT. Muscle performance, size, and safety responses after eight weeks of resistance training and protein supplementation: a randomized, double-blinded, placebo-controlled clinical trial. ] Strength Cond Res. 2013; 27(11): 3091-100.

(43) Cruz-Jentoft AJ, Landi F, Schneider SM, Zúñiga C, Arai H, Boirie $Y$, et al. Prevalence of and interventions for sarcopenia in ageing adults: a systematic review. Report of the International Sarcopenia Initiative (EWGSOP and IWGS). Age Ageing. 2014; 43(6): 748-59.

(44) Boone CH, Stout JR, Beyer KS, Fukuda DH, Hoffman JR. Muscle strength and hypertrophy occur independently of protein supplementation during short-term resistance training in untrained men. Appl Physiol Nutr Metab. 2015; 40(8): 797-802.

(45) Kirby TJ, Triplett NT, Haines TL, Skinner JW, Fairbrother KR, McBride JM. Effect of leucine supplementation on indices of muscle damage following drop jumps and resistance exercise. Amino Acids. 2012; 42(5): 1987-96.

(46) Ferreira MP, Li R, Cooke M, Kreider RB, Willoughby DS. Periexercise coingestion of branched-chain amino acids and carbohydrate in men does not preferentially augment resistance exercise-induced increases in phosphatidylinositol 3 kinase/protein kinase B-mammalian target of rapamycin pathway markers indicative of muscle protein synthesis. Nutr Res. 2014; 34(3): 191-8.

(47) Verdijk LB, Jonkers RA, Gleeson BG, Beelen M, Meijer K, Savelberg $\mathrm{HH}$, et al. Protein supplementation before and after exercise does not further augment skeletal muscle hypertrophy after resistance training in elderly men. Am J Clin Nutr. 2009; 89(2): 608-16.

(48) Kumar V, Atherton PJ, Selby A, Rankin D, Williams J, Smith K, et al. Muscle protein synthetic responses to exercise: effects of age, volume, and intensity. J Gerontol A Biol Sci Med Sci. 2012; 67(11): 1170-7.
(49) Erskine RM, Fletcher G, Hanson B, Folland JP. Whey protein does not enhance the adaptations to elbow flexor resistance training. Med Sci Sports Exerc. 2012; 44(9): 1791-800.

(50) Weisgarber KD, Candow DG, Vogt ESM. Whey protein before and during resistance exercise has no effect on muscle mass and strength in untrained young adults. Int J Sport Nutr Exerc Metab. 2012; 22(6): 463-9.

(51) Kerksick CM, Rasmussen C], Lancaster SL, Magu B, Smith $P$, Melton $C$, et al. The effects of protein and amino acid supplementation on performance and training adaptations during ten weeks of resistance training. J Strength. 2006; 20(3): 643-53.

(52) Blomstrand E. A role for branched-chain amino acids in reducing central fatigue. J Nutr. 2006; 136(2): 544S-7S.

(53) Newsholme EA, Blomstrand E. Branched-chain amino acids and central fatigue. J Nutr. 2006; 136(Suppl 1): 274S-6S.

(54) Folland JP, Williams AG. The adaptations to strength training: morphological and neurological contributions to increased strength. Sports Med. 2007; 37(2): 145-68.

(55) White JP, Wilson JM, Austin KG, Greer BK, St John N, Panton LB. Effect of carbohydrate-protein supplement timing on acute exercise-induced muscle damage. J Int Soc Sports Nutr. 2008; 5: 5

(56) Pencharz PB, Elango R, Ball RO. Determination of the tolerable upper intake level of leucine in adult men. J Nutr. 2012; 142(12): 2220S-4S.

(57) Kerksick C, Harvey T, Stout J, Campbell B, Wilborn C, Kreider R, et al. International Society of Sports Nutrition position stand: nutrient timing. J Int Soc Sports Nutr. 2008; 5: 17.

(58) Phillips S. Protein consumption and resistance exercise: maximizing anabolic potential. Sports Sci Exch. 2013; 26(107): 1-5.

(59) van Loon $\mathrm{L}$. Is there a need for protein ingestion during exercise? Sports Med. 2014; 44(Suppl 1): S105-11.

(60) Reidy PT, Walker DK, Dickinson JM, Gundermann DM, Drummond MJ, Timmerman KL, et al. Protein blend ingestion following resistance exercise promotes human muscle protein synthesis. J Nutr. 2013; 143(4): 410-6.

(61) Burke LM, Hawley JA, Ross ML, Moore DR, Phillips SM, Slater $G R$, et al. Preexercise aminoacidemia and muscle protein synthesis after resistance exercise. Med Sci Sports Exerc. 2012; 44(10): 1968-77.

(62) Churchward-Venne TA, Burd NA, Mitchell CJ, West DWD, Philp A, Marcotte GR, et al. Supplementation of a suboptimal protein dose with leucine or essential amino acids: effects on myofibrillar protein synthesis at rest and following resistance exercise in men. J Physiol. 2012; 590(Pt 11): 2751-65.

(63) Reitelseder S, Agergaard J, Doessing S, Helmark IC, Lund P, Kristensen NB, et al. Whey and casein labeled with L-[1-13C] leucine and muscle protein synthesis: effect of resistance exercise and protein ingestion. Am J Physiol Endocrinol Metab. 2011; 300(1): E231-42.

(64) Atherton PJ, Smith K, Etheridge T, Rankin D, Rennie MJ. Distinct anabolic signalling responses to amino acids in C2C12 skeletal muscle cells. Amino Acids. 2010; 38(5): 1533-9.

(65) Koopman R, Wagenmakers AJM, Manders RJF, Zorenc AHG, Senden JMG, Gorselink $M$, et al. Combined ingestion of protein 
and free leucine with carbohydrate increases postexercise muscle protein synthesis in vivo in male subjects. Am J Physiol Endocrinol Metab. 2005; 288(4): E645-53.

(66) Dreyer HC, Drummond MJ, Pennings B, Fujita S, Glynn EL, Chinkes $\mathrm{DL}$, et al. Leucine-enriched essential amino acid and carbohydrate ingestion following resistance exercise enhances mTOR signaling and protein synthesis in human muscle. Am J Physiol Endocrinol Metab. 2008; 294(2): E392-400.

(67) Burd NA, Yang Y, Moore DR, Tang JE, Tarnopolsky MA, Phillips SM. Greater stimulation of myofibrillar protein synthesis with ingestion of whey protein isolate $\mathrm{v}$. micellar casein at rest and after resistance exercise in elderly men. $\mathrm{Br}$ ] Nutr. 2012; 108(6): 958-62.
(68) Dideriksen KJ, Reitelseder S, Petersen SG, Hjort M, Helmark IC, Kjaer $M$, et al. Stimulation of muscle protein synthesis by whey and caseinate ingestion after resistance exercise in elderly individuals. Scand J Med Sci Sports. 2011; 21(6): e372-83.

(69) Phillips SM, Van Loon LJ. Dietary protein for athletes: from requirements to optimum adaptation. J Sports Sci. 2011; 29(Suppl 1): S29-S38.

(70) Phillips SM. Dietary protein requirements and adaptive advantages in athletes. $\mathrm{Br}$ ] Nutr. 2012; 108(Suppl 2): S158-S67. 